\title{
Differential effects of amyloid- $\beta$ peptide aggregation status on in vivo retinal neurotoxicity
}

This article was published in the following Dove Press journal:

Eye and Brain

9 September 2010

Number of times this article has been viewed

\author{
HR Watts' \\ PJB Anderson' \\ $\mathrm{D} \mathrm{Ma}{ }^{2}$ \\ KL Philpott ${ }^{3}$ \\ SM Jen' \\ M Croucher' \\ LS Jen' \\ SM Gentleman' \\ 'Department of Medicine, Imperial \\ College London, Charing Cross \\ Campus, London, UK; ${ }^{2}$ Department \\ of Surgery and Cancer, Imperial \\ College London, Chelsea and \\ Westminster Hospital, London, UK; \\ ${ }^{3}$ Neurosciences, Centre of Excellence \\ for Drug Discovery, GlaxoSmithKline \\ Pharmaceuticals, Harlow, Essex, UK; \\ HR Watts and PJB Anderson \\ contributed equally to this paper
}

Correspondence: Steve M Gentleman Department of Medicine, Imperial College London, Charing Cross Campus, Fulham Palace Rd, London W6 8RF, UK Email s.gentleman@imperial.ac.uk

\begin{abstract}
The present study examined the relationship between amyloid beta (A $\beta$ )-peptide aggregation state and neurotoxicity in vivo using the rat retinal-vitreal model. Following single unilateral intravitreal injection of either soluble $A \beta_{1-42}$ or $A \beta_{1-42}$ preaggregated for different periods, retinal pathology was evaluated at 24 hours, 48 hours, and 1-month postinjection. Injection of either soluble $A \beta(\mathrm{s} A \beta)$ or preaggregated $A \beta$ induced a rapid reduction in immunoreactivity (IR) for synaptophysin, suggesting that direct contact with neurons is not necessary to disrupt synapses. Acute neuronal ionic and metabolic dysfunction was demonstrated by widespread loss of IR to the calcium buffering protein parvalbumin (PV) and protein gene product 9.5, a component of the ubiquitin-proteosome system. Injection of $\mathrm{sA} \beta$ appeared to have a more rapid impact on PV than the preaggregated treatments, producing a marked reduction in PV cell diameters at 48 hours, an effect that was only observed for preaggregated $A \beta$ after 1-month survival. Extending the preaggregation period from 4 to 8 days to obtain highly fibrillar A $\beta$ species significantly increased the loss of choline acteyltransferase IR, but had no effect on PV-IR. These findings prompt the conclusion that $\mathrm{A} \beta$ assembly state has a significant impact on in vivo neurotoxicity by triggering distinct molecular changes within the cell.
\end{abstract}

Keywords: Alzheimer disease, retina

\section{Introduction}

Amyloid beta $(A \beta)$ is a small peptide of 39-43 amino acids that appears to play a central role in the genesis of Alzheimer disease (AD); a chronic neurodegenerative disorder characterized by extracellular plaques, neurofibrillary tangles, and ultimately neuronal loss. In addition, $A \beta$ deposition has been identified in certain cerebrovascular disorders and retinopathy including glaucoma. ${ }^{1}$ Insoluble and soluble deposits derived from different amyloidogenic proteins have also been implicated in neurodegenerative disorders such as Parkinson disease, Huntington, and prion-related illnesses. Together, these findings have prompted the emerging concept that aggregation-prone proteins may share common structural features and a common mechanism of neurotoxicity. ${ }^{2}$

$\mathrm{A} \beta$ is generated by the proteolytic cleavage of amyloid precursor protein (APP) during normal metabolism and is not a pathological product by itself. However, the relative amount of the 42 amino acid form $\left(A \beta_{1-42}\right)$ is particularly important as this peptide is more prone to self-aggregate than other $A \beta$ species. ${ }^{3}$ Excessive accumulation of $A \beta_{1-42}$ is thought to be one of the earliest events in $A D$, initiating a sequence of pathological processes collectively termed the amyloid cascade hypothesis. ${ }^{4}$

Modeling the cellular mechanisms underlying AD has been challenging, initially due to difficulties in establishing that $A \beta$ was indeed toxic to neurons. Under culture 
conditions, fresh solutions of $\mathrm{A} \beta_{1-42}$ were nontoxic; however, tested 24 hours later the same solutions were lethal to neurons. ${ }^{5}$ Left to incubate, the $A \beta$ peptides had undergone aggregation into large fibrils, indistinguishable from the amyloid structures found in Alzheimer plaques. Importantly, preaggregated solutions of $A \beta_{1-42}$ also displayed neurotoxicity in vivo. ${ }^{6}$ Inflammatory mechanisms represent a second challenge for models of $\mathrm{AD}$, as the capacity of $\mathrm{A} \beta$ to induce neuronal degeneration can become greatly magnified by in vivo inflammatory responses. Notably, the ability of $\mathrm{A} \beta$ to directly trigger the proinflammatory complement cascade, precipitating the destruction of otherwise healthy neurons. ${ }^{7}$ Inflammatory mediators may also stimulate APP processing and, therefore, establish a vicious cycle, rendering a relatively slowly progressing condition into one characterized by rapid degeneration. ${ }^{8}$

Although aggregation and potentiation by inflammatory factors provide a strong foundation for the role of $A \beta$ as the prime toxic entity in $\mathrm{AD}$, a third obstacle and frequently cited flaw in the amyloid hypothesis is the failure of senile plaques to adequately account for memory loss. The number of large plaques of fibrillar $A \beta$ does not correlate well with the severity of dementia and cannot explain early memory loss, which can significantly precede neurodegeneration. ${ }^{9}$ However, recent studies indicate that early memory loss results from a failure of synaptic function, not neuron death, and that the crucial pathogens are small soluble $\mathrm{A} \beta$ (sA $\beta$ ) species, rather than fibrils. In fact, levels of sA $\beta$ oligomers show robust correlation with both synaptic loss and the severity of cognitive impairment in AD. ${ }^{10-13}$

"Soluble A $\beta$ " loosely describes any $A \beta$ species of a nonfibrillar nature including $4 \mathrm{kDa}$ monomers, small oligomers termed $\mathrm{A} \beta$-derived diffusible ligands (ADDLs), and larger intermediates in excess of $100 \mathrm{kDa} .{ }^{14}$ Although there is now considerable support for the view that $\mathrm{sA} \beta$ species induce early memory deficits, whereas fibrillar $A \beta$ and the accompanying inflammatory response contribute to later impairment, it has become apparent that even among prefibrillar assemblies, the mechanism and extent of $\mathrm{A} \beta$ toxicity can differ markedly. ${ }^{15}$ One reason for continuing uncertainty about the nature of pathological $A \beta$ species is that the aggregation state of $A \beta$ is extremely flexible, for instance, in vitro incubation of $A \beta_{1-42}$ typically produces a pool of small, stable oligomers from which $A \beta$ intermediates may continue to polymerize or depolymerize depending on local conditions. ${ }^{16,17}$ Moreover, conformation differences also exist between oligomers of the same size, influencing toxicity. Many lines of evidence indicate that synthetic $\mathrm{A} \beta$ species and those derived from $\mathrm{AD}$ brain are equivalent in this respect. For example, the small oligomeric species observed upon incubation of synthetic $A \beta$ also occur under native conditions, ${ }^{11,18}$ and oligomers from both sources show attachment to neuronal cell surfaces in identical, ligand-like patterns. ${ }^{19,20}$

The most widely used models of AD, transgenic mice, do not provide a direct means to test the effects of different $\mathrm{A} \beta$ forms on the development of neuropathology and show limited neuronal death. ${ }^{21}$ For this reason, it is vitally important to establish animal models that replicate key features of $\mathrm{AD}$ after injection of a known formulation of $\mathrm{A} \beta$. The rodent retinal-vitreal model provides a well-defined CNS microsystem to monitor the effects of $A \beta$ on different CNS cell types in vivo. Our investigations to date have suggested that a single intravitreal injection of preaggregated $A \beta_{1-42}$ can precipitate degenerative changes in multiple interacting cellular systems including neuronal apoptosis, severe glial activation, immune reactivity, and blood retinal barrier breakdown. ${ }^{6,22-24}$

The aim of the present study was to clarify the relationship between $A \beta$ aggregation state and neurotoxicity in vivo. To this end, we have compared $A \beta_{1-42}$ prepared under conditions that favor either (1) sA $\beta$ (monomers and small oligomers), or solutions that have been (2) preincubated for several days to increase fibril formation, or (3) preincubated for an extended period to obtain highly fibrillar $A \beta$ species. Retinal pathology was evaluated at acute and chronic time points to identify which formulations generate reproducible neurodegenerative alterations resembling those observed in human $\mathrm{AD}$ brain tissue.

\section{Materials and methods}

\section{Animals and experimental procedures}

Amyloid peptides $\left(A \beta_{1-42}\right.$ and $\left.A \beta_{42-1}\right)$ were supplied by California Peptide Inc (California, USA) and Bachem (Merseyside, UK). Peptides were first dissolved in sterile phosphate buffered saline (PBS; 0.1M, pH 7.4) and sonicated for 1 minute. $A \beta$ working solutions of $2 \mathrm{nmol}$ and $5 \mathrm{nmol}$ were prepared, yielding final intravitreal concentrations of $40 \mu \mathrm{M}$ and $100 \mu \mathrm{M}$, respectively. Fresh $\mathrm{A} \beta$ solutions were stored at $-20^{\circ} \mathrm{C}$, or for preaggregated preparations, were incubated at $37^{\circ} \mathrm{C}$ for either 4 or 8 days. The former to act as a direct comparison with our previous studies. ${ }^{6,22,25}$ It was noted that preaggregated $A \beta$ peptides became highly viscous following incubation and exhibited both particulate and larger precipitates under the light microscope. We have previously confirmed that this change in viscosity correlates with positive staining for Congo Red, ${ }^{23}$ indicative of the presence 
of $A \beta$ fibrils and aggregates. Soluble $A \beta$ preparations did not display any increased viscosity and lacked any visible indication of precipitated aggregates.

Female Sprague-Dawley rats weighing 150-350 g were divided into 9 groups including 1 group of naïve controls $(\mathrm{n}=4)$ and 8 treatment groups receiving a $3 \mu \mathrm{L}$ unilateral intravitreal injection of (1) PBS $(n=5)$ or PBS containing one of the following: (2) $5 \mathrm{nmol}$ of $\mathrm{A} \beta_{42-1}$ reverse peptide $(\mathrm{n}=10)$; (3) $2 \mathrm{nmol}$ of $\mathrm{sA} \beta_{1-42}(\mathrm{n}=3)$; (4) $2 \mathrm{nmol}$ of $\mathrm{A} \beta_{1-42}$ preaggregated for 4 days $(n=3)$; (5) $5 \mathrm{nmol}$ of $\mathrm{sA} \beta_{1-42}(\mathrm{n}=5)$; (6) $5 \mathrm{nmol}$ of $\mathrm{A} \beta_{1-42}$ preaggregated for 4 days $(\mathrm{n}=12)$; (7) $5 \mathrm{nmol}$ of $A \beta_{1-42}$ preaggregated for 8 days $(n=12)$. For the final group, having determined that findings did not differ between $A \beta_{1-42}$ obtained from either California Peptide Inc or Bachem, data from the 2 treatments were pooled to provide (8) $5 \mathrm{nmol}$ of $\mathrm{A} \beta_{1-42}$ preaggregated 8 days $(\mathrm{n}=14)$ for a 1-month survival group. A $\beta$ peptides supplied by California Peptide Inc were used for all other treatments.

All surgical procedures were performed in accordance with the UK Animals (Scientific Procedures) Act 1986. Rats were anesthetized with a mixture of ketamine/xylazine ( $0.25 \mathrm{~mL} / 100 \mathrm{~g}$ body weight) before intravitreal injection and allowed to survive for 24 hours, 48 hours, or 1 month before being deeply anesthetized by overdose with sodium pentobarbital followed by perfusion with $4 \%$ paraformaldehyde in PBS. Before injection, a small amount of vitreous fluid was withdrawn to avoid any increase in intraocular pressure. Care was taken to avoid damaging the lens and any unnecessary stress to the animals. All perfusion fixation was carried out at the same time of day to minimize physiological variation in protein levels that undergo diurnal rhythm in rats (eg, parvalbumin [PV]). Following perfusion, eyeballs were removed and postfixed in the same fixative overnight, before sinking in $30 \%$ sucrose solution prior to cryoprotection. Eyeballs were sectioned on a cryostat at $20 \mu \mathrm{m}$ thickness, mounted on gelatinized slides and stored at $-20^{\circ} \mathrm{C}$.

\section{Immunohistochemistry}

Immunostaining was performed on cryostat sections using the following primary antibodies: mouse antisynaptophysin (1:200, Chemicon), mouse antiparvalbumin (1:1,000, Sigma), rabbit antiprotein gene product 9.5 (PGP 905; 1:100, DakoCytomation), goat anticholine acteyltransferase (ChAT; 1:200, Chemicon), mouse antinestin (1:1000, Chemicon), and mouse antiglial fibrillary acid protein (GFAP; 1:1,000 Sigma). Sections were incubated with primary antibodies overnight and processed according to the avidin-biotin complex method (Vector Labs, UK) and visualized using a DAB peroxidase substrate kit (Vector Labs). For fluorescence, secondary antibodies and flurophores were as follows: Biotinylated horse antimouse (1:100) with streptavidin-alexa 488 (1:1,000), Cy-3 conjugated rabbit antimouse IgG (1:200), Cy-3 conjugated rabbit antigoat IgG (1:200) and Cy-3 conjugated goat antirabbit IgG, (1:200), $553 \mathrm{~nm}$ (Jackson Immunoresearch Europe, Ltd), DAPI nuclear stain (Vector Labs). Control sections were incubated with the primary antibody replaced by PBS or normal serum. Nissl-stained sections, prepared using $0.1 \%$ cresyl violet, were used to examine the cytoarchitecture of the retina and to detect pyknotic nuclei.

\section{Quantitative histology}

Analysis of tissue sections was carried out using an Olympus AH-3 light microscope or Nikon E1000M fluorescence microscope, both equipped with a CCD color video camera and Image-Pro Plus 6.0 (Media Cybernetics Inc, Silver Spring, USA) image analysis system. Noninjected (right) and injected (left) retinas were digitized using identical exposure settings. For quantitative histology, all immunostaining was run in duplicate or triplicate. Final quantitative assessments were conducted on 4 representative sections per retina. Three segments (400 $\mu \mathrm{m}$ in length) of each section were assessed, consisting of the optic region and 2 equidistant central regions. To evaluate the reproducibility of quantitative methods, all analyses were conducted twice (1 month apart) with experimenters blind to treatments.

Measurement of synaptophysin immunostaining was carried out on intensity calibrated grayscale images captured at $20 \times$ magnification. The optical density (OD) value of synaptophysin immunoreactivity (IR) in the outer plexiform layer (OPL) and inner plexiform layer (IPL) was determined using semi-quantitative densitometric analysis. OPL peaks were obtained from whole retinal profiles. Separate measurements were conducted for the IPL by sampling blocks of 200-400 $\mu \mathrm{m}$ length (depending on the curvature of the retina) to provide a mean value for each retina. For comparison between treatment groups and PBS controls, transformed data (experimental densitometry value/PBS control densitometry value $100 \times$ ) were evaluated by ANOVA and a post hoc Tukey's test.

Quantification of PV and ChAT immunostaining was performed using a semi-automated method on spatially calibrated images captured at $20 \times$ magnification and viewed at $200 \%$ optical zoom. Briefly, a threshold procedure was used to establish the lowest optical intensity for reasonable positive labeling of somata in the right (noninjected) retina. The same parameter was then applied to the left (injected) 
retina. A threshold was determined for each pair of sections, although in practice threshold parameters were comparable across all tissue as efforts were made to minimize methodological variations. Finally, a filter was applied to exclude objects $<3 \mu \mathrm{m}$, before counts and diameter measurements were performed manually on highlighted somata.

Retinal thickness (distance from the ganglion layer to the outer nuclear layer inclusively) was determined on nisslstained sections by taking measurements from equidistant central retina locations (20 per retina). Quantified data were evaluated for an approximately normal distribution and paired $t$-tests used to assess the significance of differences between the injected (left) eyes and noninjected (right) eyes. For comparison between treatment groups and PBS controls, 1-way ANOVA on injected (left) eyes and a post hoc Dunnett's tests were performed. Other comparisons between groups were performed using post hoc Tukey's tests. Values are expressed as a percentage of PBS controls unless otherwise stated and are given as mean \pm standard error of the mean (SEM). Differences were considered significant at the level of $P \leq 0.05$.

\section{Results}

\section{Acute synaptic responses to $A \beta_{1-42}$ treatment in the rat retina}

In noninjected (right) eyes (Figure $1 \mathrm{~A}-\mathrm{C}$ ), immunostaining for synaptophysin produced intense reactivity throughout the IPL and OPL. Intravitreal injection of PBS $(3 \mu \mathrm{L})$ produced no discernible loss of synaptophysin-IR at 48-hour survival (Figure 1D). By contrast, injection of either sA $\beta$ or 4 -day preaggregated $A \beta_{1-42}$ resulted in a marked loss of staining among processes throughout the IPL as shown in Figure 1E and $\mathrm{F}$ and the corresponding OD profiles.

Densitometric analysis of the IPL revealed significant differences between groups ( $P=0.0014$; ANOVA). A $\beta_{42-1}$ reverse peptide injections $(5 \mathrm{nmol} / 3 \mu \mathrm{L})$ produced no significant reduction in synaptophysin-IR, relative to PBS controls. Synatophysin-IR loss was greatest among $A \beta_{1-42}$ groups injected with a high dose $(5 \mathrm{nmol})$ of aggregated $\mathrm{A} \beta_{1-42}$, with over $40 \%$ loss of staining for both the 24 -hour survival and 48-hour survival treatments compared with the control peptide (both $P<0.01$; Figure 2). In addition, sA $\beta$ administered at the lower dose $(2 \mathrm{nmol})$ produced a marked reduction in synatophysin staining at 48 hours relative to $\mathrm{A}_{42-1}$ controls $(P<0.05)$.

For the majority of $A \beta_{1-42}$-injected retinas, synaptophysin-IR in the OPL was largely preserved, despite loss of IPL staining (Figure 1E). Marked loss of OPL-IR was observed in small regions of retinas in a few cases at 48-hour survival (Figure 1F); however, differences between groups were nonsignificant (OPL data and further images are supplied in Supplementary Figure 1). In no instance was a decrease in OPL synaptophysin-IR detected in the absence of a decline in the IPL, suggesting IPL synapses are more acutely susceptible to the effects of intravitreal $\mathrm{A} \beta$ injection.

\section{$A \beta$-induced alterations in metabolic activity}

The effect of intravitreal $A \beta$ injection on intracellular metabolic processes was investigated by (1) quantifying neurons that are rich in the calcium-binding protein PV and (2) examining the distribution of PGP 9.5; a neurone-specific cytoplasmic protein involved in the disassembly of ubiquitin protein conjugates formed during protein metabolism.

In noninjected and naïve retinas, PV-IR was prominent among amacrine cells along the inner margin of the inner nuclear layer (INL) and in a subpopulation of ganglion cells. PV-IR displayed a marked sensitivity to all $A \beta$ preparations, including the $\mathrm{A} \beta_{1-42}$ reverse sequence (all $P<0.01$, paired $t$-tests, compared with noninjected eyes; Figure 4A). A modest reduction in PV-IR after PBS injection did not differ significantly from naïve tissue. Loss of PV-IR was greatest among sA $\beta$ and 4-day preaggregated $A \beta_{1-42}$ groups, ranging from $26 \%$ reduction to a near-complete loss of PV-IR except for a few weakly immunoreactive somata (Figure $3 \mathrm{~B}$ and C). Retinas receiving injections of $\mathrm{sA} \beta$ were also the only group to display a reduction in cell diameters at 48-hour postinjection (3-16 $\mu \mathrm{m}$, compared with 3-20 $\mu \mathrm{m}$ for PBS; $P<0.01$, Figure 4B). No significant effect of incubation period (A $\beta_{1-42}$ preaggregated for 4 or 8 days) was noted at 48-hour survival. At 1 month following injection of $A \beta_{1-42}$ (8-day incubation), marked recovery of PV-IR was observed, despite a substantial loss of retinal thickness (Figure 4A). However, recovery was more prominent among smaller somata, resulting in a significant reduction in cell diameters relative to PBS controls ( $P<0.01$; Figure 4B). Abnormalities in the pattern of PV-IR were also evident at 1 month, including disorganized somata and punctate rather than fine process labeling in the IPL (Figure 3E and F).

PGP 9.5 IR in noninjected eyes was most intense among retinal ganglion cells and INL somata. Prominent labeling of plexiform strata was also present (Figure 5A). PGP 9.5 was not detected in photoreceptors, although faint labeling of retinal pigment epithelium was often visible. Injection with the $\mathrm{A} \beta_{42-1}$ reverse peptide resulted in a modest downregulation 
PBS Control
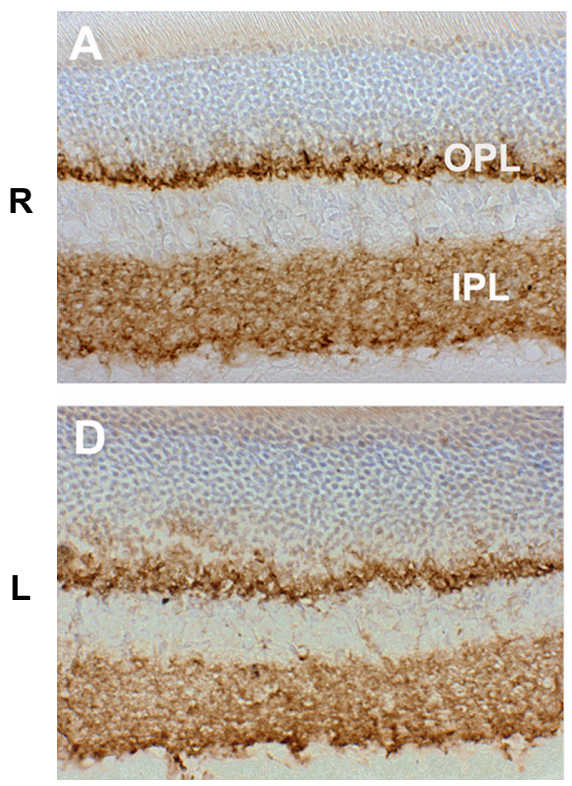

$A \beta_{1-42}$ Aggregated
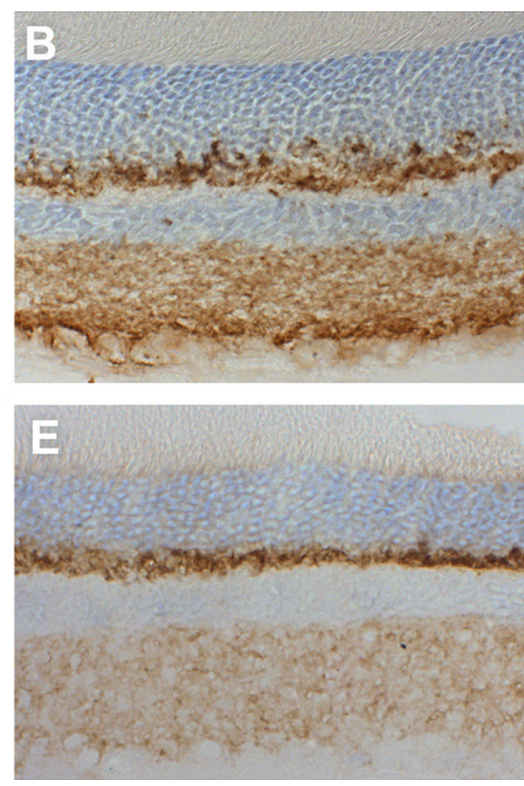

$A \beta_{1-42}$ Soluble
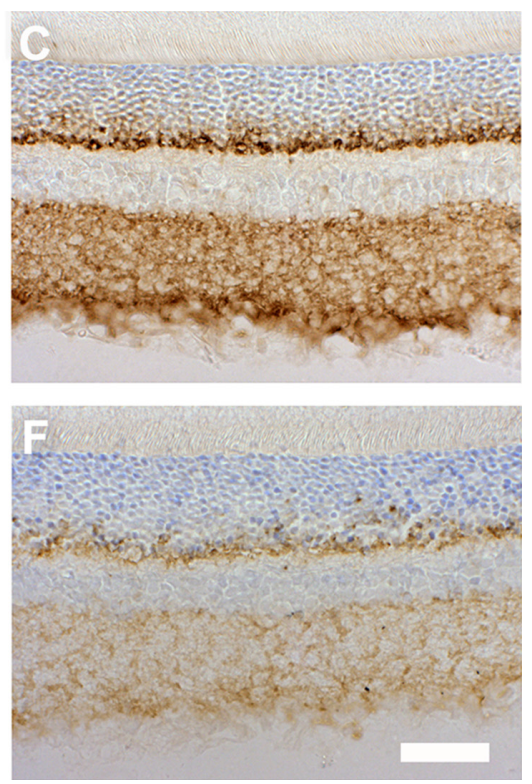
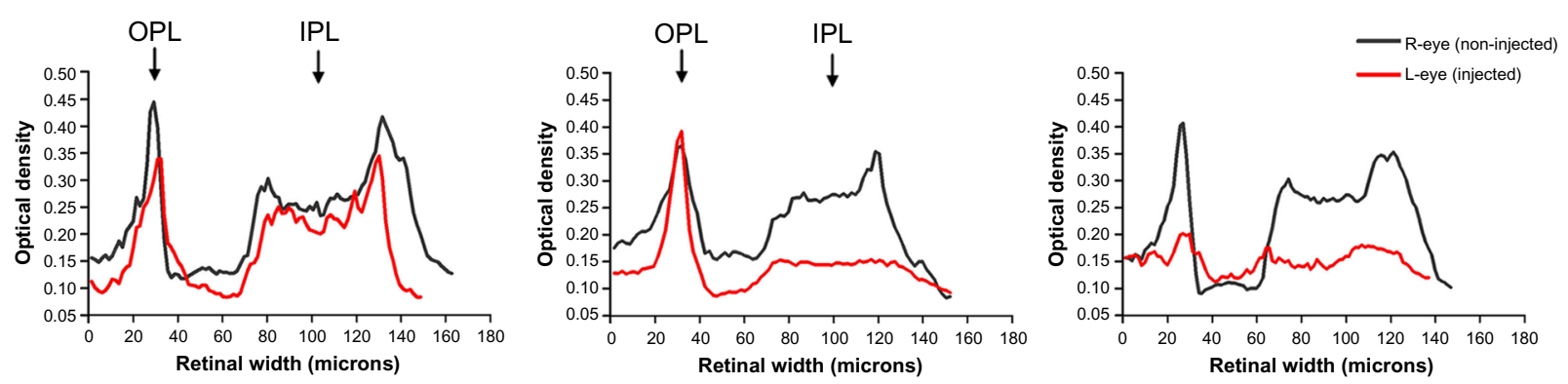

Figure I Synaptophysin immunoreactivity in retinas from noninjected (right) eyes (top panel) and injected (left) eyes (middle panel) at 48 hours following intravitreal injection of either phosphate buffered saline (PBS), soluble $A \beta_{I-42}(2 \mathrm{nmol} / 3 \mu \mathrm{L})$ or at 24 hours following injection of aggregated $A \beta_{I-42}(5 \mathrm{nmol} / 3 \mu \mathrm{L})$, incubated for 4 days. Optical density profiles for the corresponding retinas (lower panel) highlight the loss of syna ptophysin-IR in the inner plexiform layer (IPL) of $A \beta_{1-42}$-injected eyes ( $\mathbf{E}$ and $\mathbf{F}$ ). Synaptophysin-IR in the outer plexiform layer (OPL) was more variable, with only a few cases showing a marked decline $(\mathbf{F})$. Scale bar $=50 \mu \mathrm{m}$.

of PGP 9.5 at 48 hours. By contrast, injection with $\mathrm{A} \beta_{1-42}$ incubated for 8 days resulted in a marked loss of PGP 9.5 IR, particularly within large somata in the INL and ganglion cell layer (GCL; Figure 5C). At 1-month survival, PGP 9.5-IR had recovered to near-control levels within the atrophied IPL and among small somata, however, the reduction in labeling of large somata persisted (Figure 5D).

\section{Prolonged decline in neurotransmitter manufacture}

To determine whether $\mathrm{A} \beta$ peptides have a detrimental effect on neurotransmitter manufacture, we assessed retinal ChAT-IR. In noninjected tissue, cholinergic amacrine neurons are highlighted by intense ChAT labeling of mirror symmetrical somata located in the INL and a layer of displaced amacrine cells in the GCL, with processes stratified in 2 distinct bands coursing the length of the IPL (Figure 6A). Following intravitreal injection of $A \beta_{1-42}$ peptides, extensive and sustained loss of ChAT immunostaining was observed ( $P<0.0007 ; 1$-way ANOVA). Results of paired $t$-tests between injected (left) and noninjected (right) eyes for each treatment are summarized in Figure 7.

ChAT-IR was not significantly altered by either injection of PBS or the $A \beta_{42-1}$ reverse peptide. Soluble $A \beta_{1-42}$ or $\mathrm{A} \beta_{1-42}$ preaggregated for 4 days produced a comparable loss of ChAT-positive somata at 48 hours $(28.3 \%$ and $25.9 \%$ loss respectively, relative to $\mathrm{PBS}$ ), although IR within processes remained strong (Figure 6D). Extending the $A \beta_{1-42}$ preaggregation period from 4 to 8 days dramatically increased the loss of ChAT cells (54.4\%, $P<0.01$ relative to PBS) and was accompanied by widespread loss of ChAT labeling among processes (Figure 6F). After 1-month survival, a few segments of retina displayed normal ChAT-IR, although recovery was nonsignificant when compared with the 48-hour group. Cholinergic cell size was also markedly reduced from a mean diameter of $7.8 \mu \mathrm{m}$ in PBS controls to below $7.5 \mu \mathrm{m}$ 


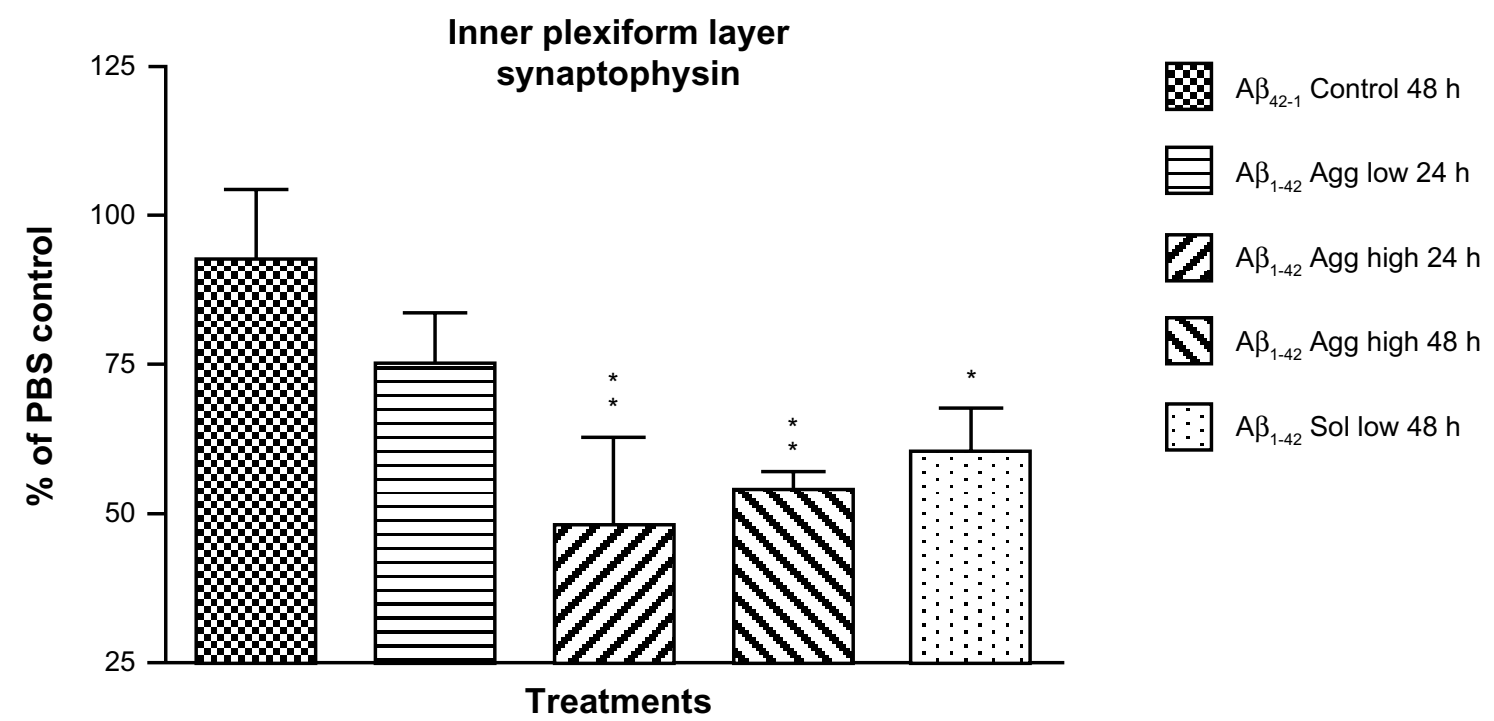

Figure 2 Mean optical density of synaptophysin immunoreactivity in the inner plexiform layer of injected eyes for groups receiving either aggregated $A \beta_{\mid-42}(2 \mathrm{nmol})$ or $(5 \mathrm{nmol})$ assessed at 24-hour postinjection, or aggregated $A \beta_{42-1}$ control peptide $(5 \mathrm{nmol})$, aggregated $A \beta_{1-42}(5 \mathrm{nmol})$ or soluble $A \beta_{1-42}(2 \mathrm{nmol})$, assessed at 48 -hour postinjection. $A 1 l$ aggregated peptides were incubated for 4 days. Values are expressed as a percentage of the phosphate buffered saline (PBS) control, given as mean \pm standard error of the mean (SEM). $* P<0.05$, **P $<0.01$ : significant reduction compared with $A \beta_{42-1}$ control peptide group (I-way ANOVA and post hoc Dunnett's test).

Abbreviations: Agg, aggregated; sol, soluble.

in $\mathrm{A} \beta_{1-42}$ retinas $(P<0.01$; Figure $7 \mathrm{~B})$. Notably, significant ChAT loss was also evident in the contralateral (noninjected) retinas after 1 month $(P<0.01$; Figures $6 \mathrm{G}$ and $7 \mathrm{~A})$.

Costaining with glial markers revealed that the acute decline in ChAT-IR was accompanied by a marked gliotic response. Induction of nestin was both more rapid and exten- sive than upregulation of GFAP. At 48 hours after injection with $\mathrm{A} \beta_{1-42}(5 \mathrm{nmol}, 8$-day preincubated), nestin expression was abundant in the endfeet region of Müller glial cells, dramatically extending into thickened distal processes in more extreme cases, as shown in Figure 8B. After 1 month, nestin levels had largely subsided in regions showing no evidence
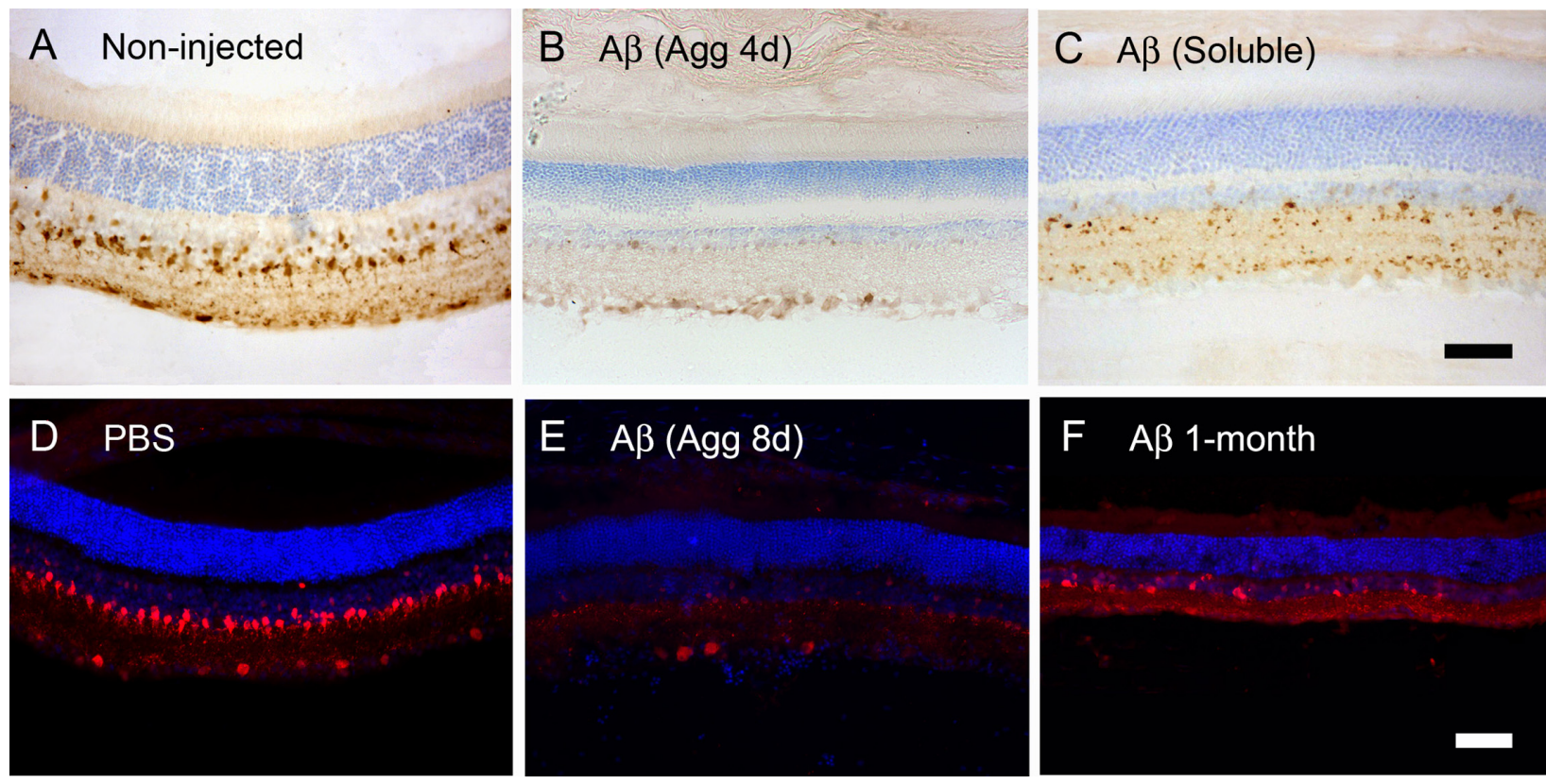

Figure 3 Parvalbumin immunostaining with cresyl violet counterstain in a normal retina $(\mathbf{A})$ and at 48 hours following injection of $A \beta_{1-42}$ incubated for 4 days $(\mathbf{B})$ or soluble $A \beta_{1-42}(\mathbf{C})$. (D and E) Fluorescence images showing parvalbumin (PV; red) with DAPI nuclear stain (blue) following injection with phosphate buffered saline (PBS; $\mathbf{D})$ or $A \beta_{1-42}$ incubated for 8 days after 48-hour survival $(\mathbf{E})$ and I-month survival $(\mathbf{F})$. Note partial recovery of PV-labeling after I month despite a marked loss of retinal thickness. Scale bars $=50 \mu \mathrm{m}$. 
A

Parvalbumin cell counts

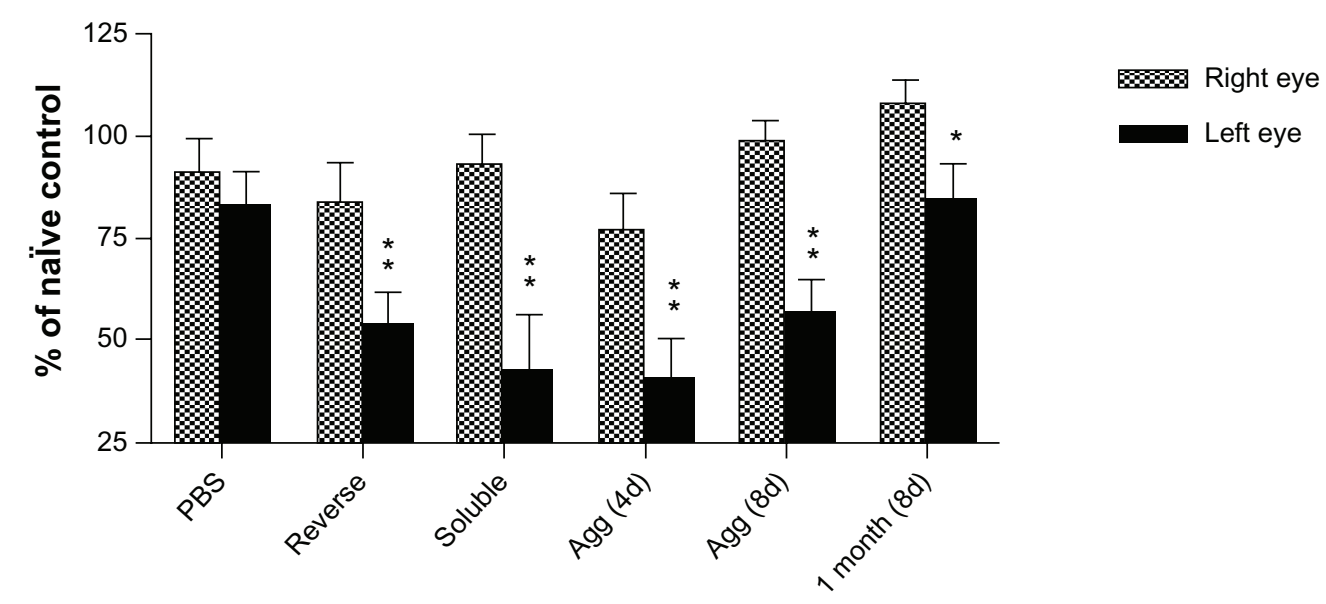

B

Parvalbumin cell size

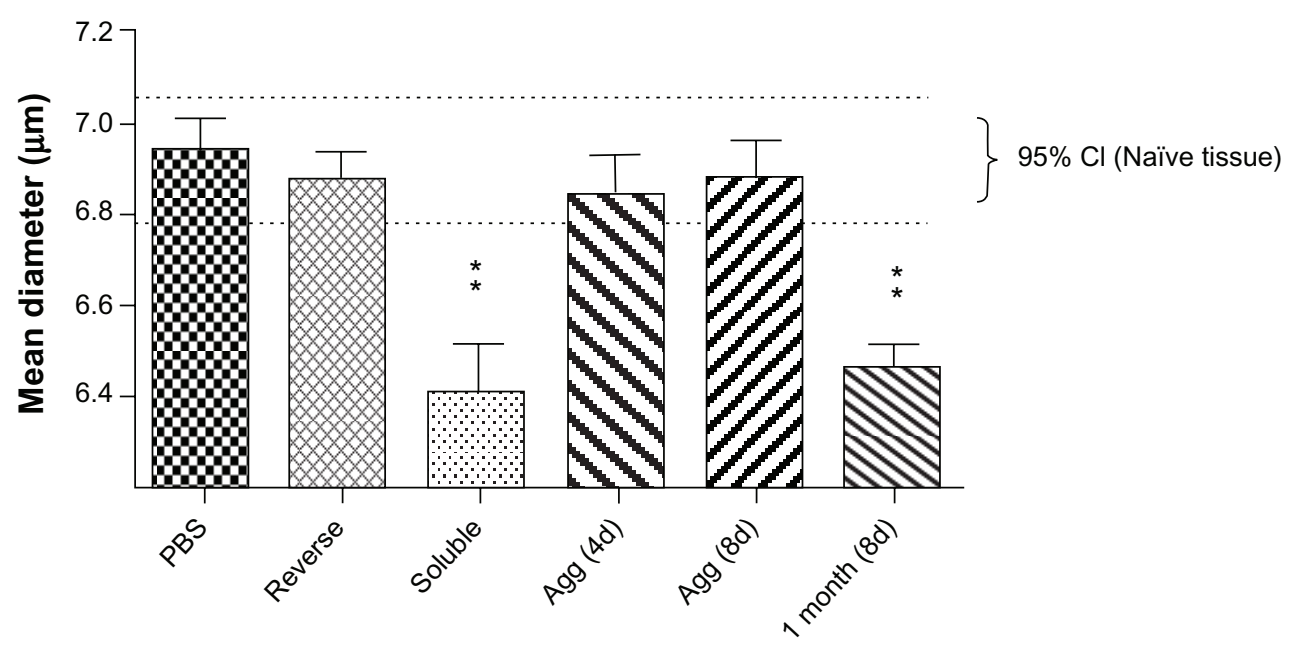

Figure 4 Reduction in parvalbumin (PV) immunoreactive (IR; $\mathbf{A})$ cell numbers and (B) cell diameters 48 hours after injection with phosphate buffered saline (PBS), $A \beta_{42-1}$ control peptide, soluble $A \beta_{\mid-42}$, $A \beta_{\mid-42}$ preaggregated for 4 or 8 days and I month after $A \beta_{\mid-42}$ preaggregated for 8 days. All peptides were injected at 5 nmol/3 $\mu$ L. Loss of PV-IR cell numbers was far less extensive at I month after injection of $A \beta_{1-42}$; however, this was accompanied by a significant reduction in average cell diameters (B). Bars represent mean \pm standard error of the mean (SEM). 95\% confidence interval $(\mathrm{Cl})$. $* \mathrm{P}<0.05, * * P<0.0 \mathrm{I}$ : significant reduction compared with $(\mathbf{A})$ noninjected eyes (paired $t$-tests), (B) with PBS controls (I-way ANOVA with a post hoc Dunnett's test).

of ChAT recovery (Figure 8C), whereas GFAP remained elevated. Strikingly however, short segments of retina (ranging from c.100 $\mu \mathrm{m}$ to a third of the retinal length) retained robust ChAT-IR and were frequently accompanied by prolonged nestin expression (Figure 8D). This regional colocalization of nestin and ChAT activity was observed in 8 out of 12 retinas showing a marked ChAT loss at 1 month and was typically, but not exclusively found towards the retinal periphery. No similar pattern of localization with ChAT-IR regions was observed for GFAP, raising the possibility that prolonged nestin induction was associated with regenerative efforts. A full description of the retinal glial responses to $A \beta_{1-42}$ injection observed in these experiments is reported separately. ${ }^{24}$

\section{Retinal atrophy at I-month survival}

Retinal thickness (distance from the ganglion layer to the ONL inclusively) was determined for central regions to provide a measure of retinal atrophy (Figure 9A). A highly significant ANOVA $(P<0.0001)$ for injected (left) eyes revealed a significant reduction in retinal thickness at 1-month survival relative to both PBS controls and $\mathrm{A} \beta_{1-42}$ treatment at 48 hours (both $P<0.001$ ). In many cases, retinas were reduced to half normal thickness, with atrophy most apparent in the IPL 

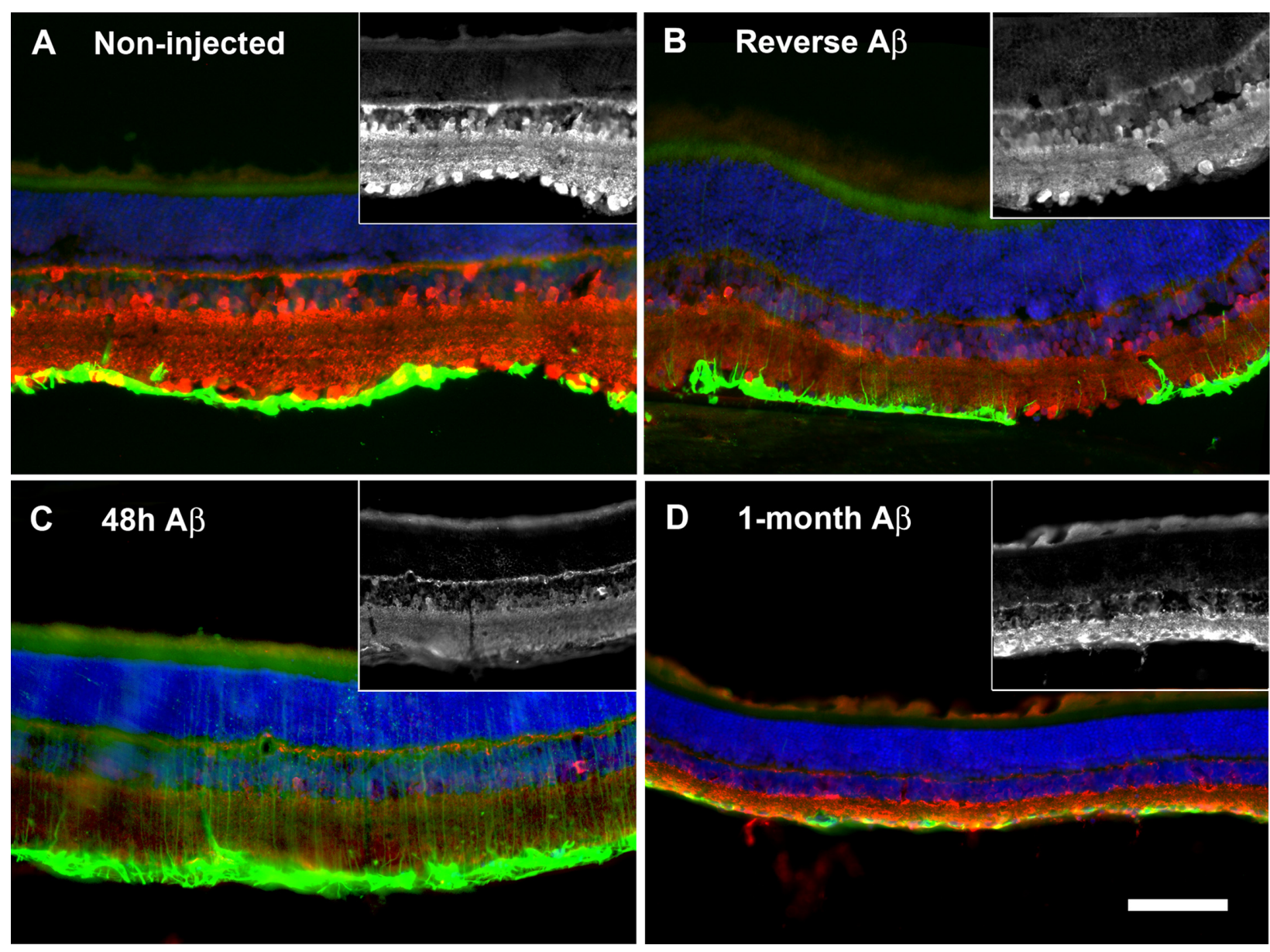

Figure 5 Retinal sections showing the distribution of protein gene product 9.5 (PGP 9.5, red) with glial fibrillary acid protein (GFAP, green) and DAPI nuclear stain (blue). Inset monochromatic images depict PGP 9.5 alone. In normal retina (A), PGP 9.5 is strongly expressed among both somata and plexiform layers of horizontal, amacrine and ganglion cells. B) Injection of $A \beta_{42-1}$ reverse sequence produced modest downregulation of PGP 9.5 and mild upregulation of GFAP after 48 hours. C) 48 hours after injection of $A \beta_{1-4}$ PGP 9.5 is clearly downregulated, particularly within large somata. GFAP levels are also markedly increased at 48-hour postinjection. D) I month after injection of $A \beta_{1-42}$ PGP 9.5 expression is largely restored within the atrophied inner plexiform layer and small somata; however, the reduction in labeling of large somata persists. All $A \beta_{1-42}$ treatments were preaggregated for 8 days. Scale bar $=100 \mu \mathrm{m}$.

and INL (reduced to 3-4 cells thick after 1 month compared with 6-8 cells for naïve tissue; Figure 9B). Moderate atrophy of contralateral (noninjected) retinas was also evident at 1 month. Surprisingly, TUNEL staining and inspection of nissl-stained sections at 48-hour postinjection did not reveal any significant cell death in the form of apoptosis or pyknotic nuclei for any treatment (results not shown), suggesting that $A \beta$-induced degenerative changes evolved gradually, rather than trigger acute neuronal loss.

\section{Discussion}

The present study demonstrates that both sA $\beta$ and preaggregated $A \beta$ species can trigger degenerative changes in multiple neuronal systems and that the profile of changes was significantly influenced by $\mathrm{A} \beta$ aggregation status. Furthermore, our investigations uniquely suggest that direct contact with neurons is not essential for $A \beta$ to induce alterations in synaptic function or the ubiquitin-proteosome system.

\section{Acute synaptic alterations induced by both $s A \beta_{1-42}$ and fibrillar $A \beta_{\mid-42}$}

The presynaptic vesicle protein synaptophysin was examined as an index of synaptic terminal dysfunction. Decreased synaptophysin has previously been shown to correlate with elevated $\mathrm{sA} \beta_{1-42}$ content in $\mathrm{AD}$ transgenic mice models and in human AD brain. ${ }^{26,27}$ Using single intravitreal injection, we have confirmed a synaptotoxic effect of $\mathrm{sA} \beta_{1-42}$ and have also demonstrated that preaggregated $A \beta_{1-42}$ peptides induce significant loss of retinal synaptophysin in a dose-dependent manner. Synaptophysin decreases rapidly (within 24 hours) and predominantly within the IPL, indicating early changes 


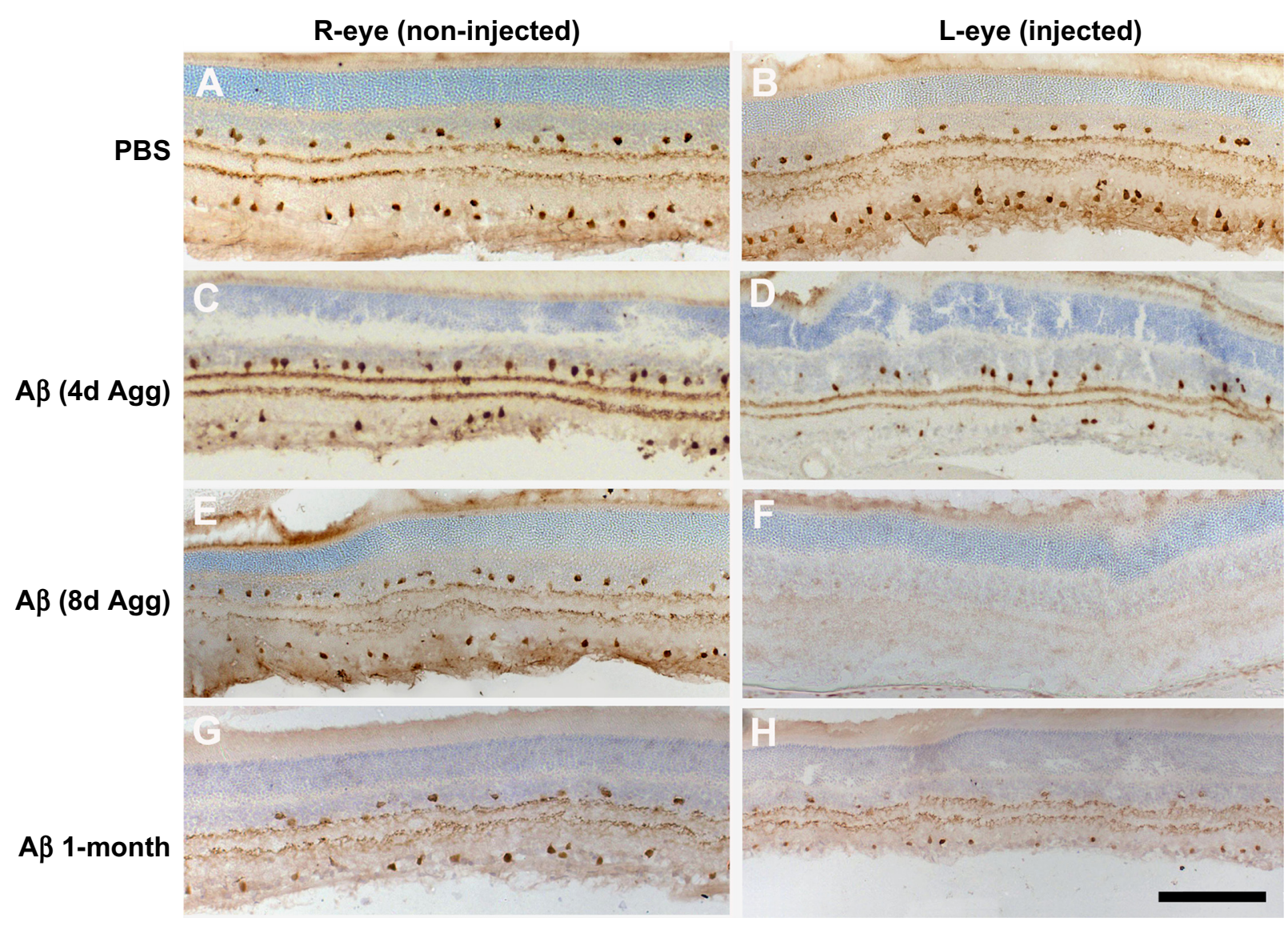

Figure 6 Choline acteyltransferase (ChAT)-immunostaining in noninjected (right) and injected (left) eyes showing (A and B) no change at 48 hours following phosphate buffered saline (PBS) injection. (C and D) Mild loss of ChAT-immunoreactivity (IR) somata 48 hours after injection with A $\beta_{1-42}$ preincubated for 4 days. (E and $\mathbf{F}$ ) Extending the preincubation period to 8 days dramatically increased ChAT loss, with weak or undetectable ChAT-IR predominant among both somata and processes in central retina. $(\mathbf{G}$ and $\mathbf{H})$ I month after injection with 8-day preincubated $A \beta_{1-42}$, loss of ChAT-IR persisted and was accompanied by a marked reduction in remaining ChAT-IR neuronal diameters. ChAT loss was also evident in the contralateral (noninjected) retina (G). Scale bar $=100 \mu \mathrm{m}$.

in synaptic connections between bipolar and ganglion cells, whereas photoreceptor terminals were largely unaffected. Although the relative proximity of the IPL to the vitreal injection site raises the possibility of simple diffusion of $A \beta$ resulting in direct disruption of neuronal synapses as previously described for small $A \beta$ oligomers and ADDLs, ${ }^{14,28}$ retinal neurons are separated from the vitreous by fused foot processes of Müller glia, presenting a barrier to diffusion and therefore direct contact with synapses. Passive diffusion has been demonstrated in selected locations such as the macula and optic disc where retinal barrier properties are diminished, permitting the passage of molecules $<15-20 \mathrm{~nm},{ }^{29}$ which could feasibly include sA $\beta$ and some proto-fibrils. ${ }^{2}$ However, simple diffusion and direct synaptic action are unlikely to have played a major role in $A \beta$-induced loss of synaptophysin for the key reason that one would expect sA $\beta$ preparations to diffuse more readily and demonstrate greater potency than preaggregated solutions containing a high proportion of $A \beta$ fibrils. Although there is some indication that $\mathrm{sA} \beta$ exerted a stronger effect than anticipated for the low dose given ( $2 \mathrm{nmol})$, it is not of the magnitude one might expect if direct diffusion was a prime mechanism.

Interestingly, although both $A \beta_{1-42}$ preparations induced synaptic alterations, only the preaggregated peptides triggered a significant glial response in the form of GFAP and nestin upregulation. ${ }^{24}$ The lack of a marked injury response to sA $\beta$ suggests that proinflammatory actions of local microglial and astrocytes do not appear to have been an important contributor to synaptic disturbance for either forms of $A \beta_{1-42}$. Together, these findings suggest a novel mechanism of $A \beta$-induced synaptic disturbance that occurs other than solely via direct synaptic interactions and that is not primarily inflammatory. The likelihood that Müller glia play a key role in mediating A $\beta$ 's retinal neurotoxicity is discussed separately later. 


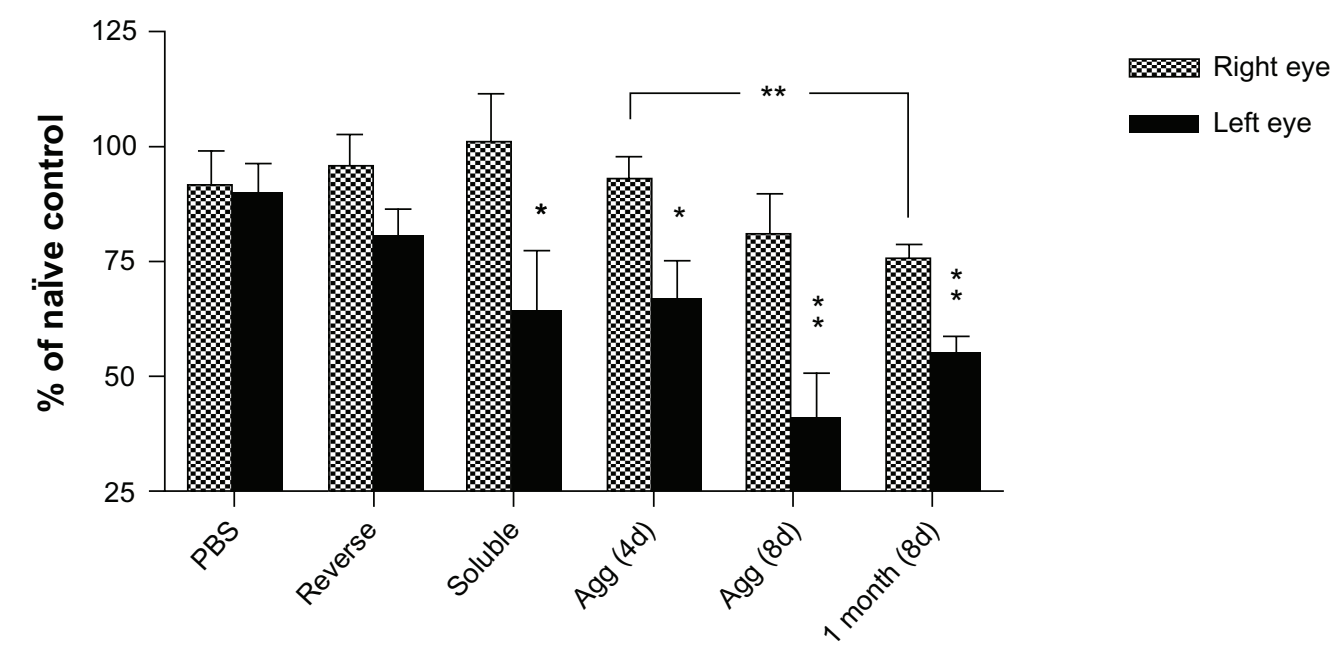

B Cholinergic cell size

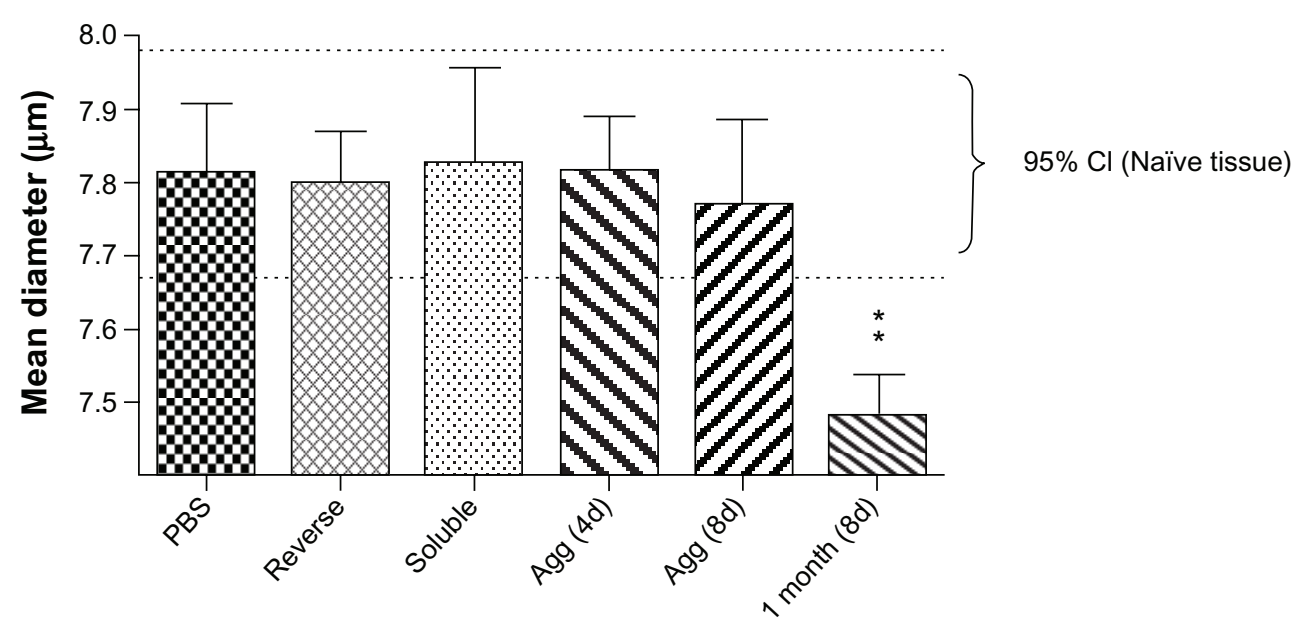

Figure 7 Reduction in choline acteyltransferase (ChAT) immunoreactive (IR) cell numbers (A) and cell diameters (B) 48-hour postinjection of phosphate buffered saline (PBS), or $5 \mathrm{nmol} A \beta_{42-1}$ control peptide, soluble $A \beta_{1-42}$ or $A \beta_{1-42}$ preaggregated for 4 days, or at 48 hours or I month after $A \beta_{1-42}$ preaggregated for 8 days. (A) Extending the preaggregation period to 8 days dramatically increased the loss of ChAT cells seen at 48 hours. Significant reduction in ChAT-IR was also evident in noninjected retinas (right-eyes) after I month (unpaired t-test). (B) Cell diameters of neurons expressing ChAT in injected (left-eyes) after I month were significantly reduced. Bars represent mean \pm standard error of the mean (SEM). $95 \%$ confidence interval $(\mathrm{Cl})$. $* P<0.05, * * P<0.01$ : significant reduction compared with $(\mathbf{A})$ noninjected eyes (paired $t$-tests) unless otherwise indicated, (B) with PBS controls (I-way ANOVA with a post hoc Dunnett's test).

\section{Selective ionic and metabolic disturbance}

A second notable finding from this study is the demonstration that $\mathrm{A} \beta_{1-42}$ injection leads to a marked reduction in PGP 9.5-IR, suggesting disturbed proteosome activity. Injection of the reverse peptide produced a modest decline in overall levels of PGP 9.5 at 48 hours; however, the normal pattern of distribution was still visible as 2 distinct bands of immunoreactive somata in the GCL and INL. By contrast, injection with highly aggregated $\mathrm{A} \beta_{1-42}$ induced a dramatic reduction in PGP 9.5-IR which persisted in the GCL for
1 month, whereas recovery was seen in the IPL. A similar pattern of decline in retinal PGP 9.5 has been reported after unilateral optic axon injury, which found c. $45 \%$ loss of GCL IR but only minor changes in the IPL. ${ }^{30}$ In this instance, selective loss of PGP 9.5 in the GCL reflects the rapid degeneration of these neurons due to loss of retrograde support. Accounting for the selective reduction in GCL PGP 9.5 levels following $A \beta_{1-42}$ injection is less clear cut, but may reflect the high metabolic demand on these cells, which process convergent inputs predominantly via 

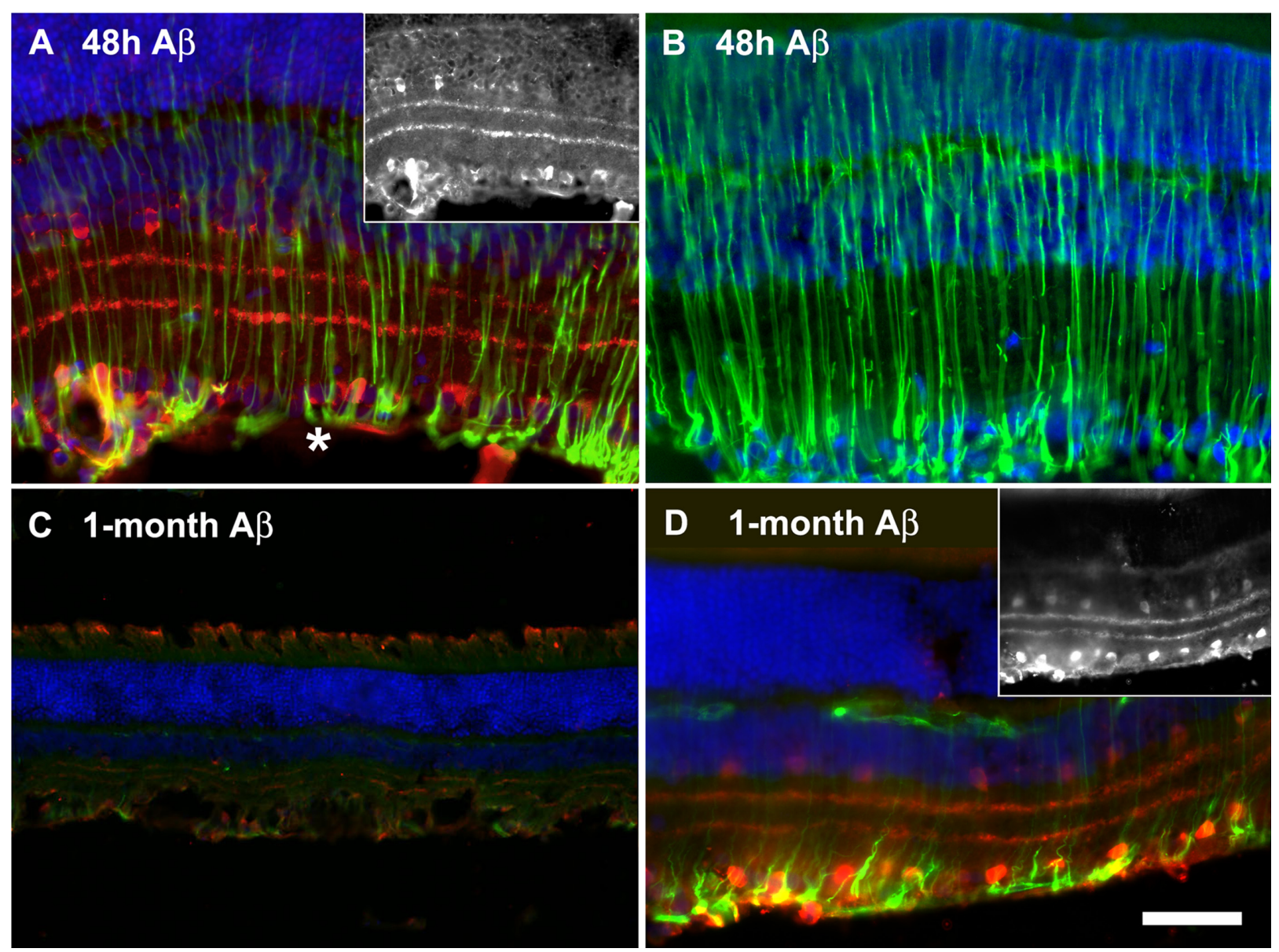

Figure 8 Fluorescence images showing retinal choline acteyltransferase (ChAT; red), nestin (green), and DAPI nuclear stain (blue). Inset monochromatic images depict ChAT alone. A) At 48 hours after injection with $A \beta_{1-42}$ (5 nmol, 8-day preincubation), declining ChAT levels were accompanied by induction of nestin. Nestin expression was most abundant in the endfeet region of Müller glial cells (asterisk in A), dramatically extending into thickened distal processes in more extreme cases (B). In regions of retina showing no evidence of ChAT recovery after I month, nestin levels had largely subsided (C). However, notably towards the periphery, short regions retaining robust ChAT activity were accompanied by prolonged nestin expression (D). Scale bar represents $50 \mu \mathrm{m}$ (A, B, D); $100 \mu \mathrm{m}$ (C).

glutamatergic signaling, rendering them more susceptible to excitotoxic stress.

As a component of the ubiquitin-proteosome system, a prolonged decline in PGP 9.5 activity may diminish a neurone's ability to maintain balanced protein metabolism. In the case of A $\beta$-induced PGP 9.5 deficits, impaired protein degradation could have a serious impact on $A \beta$ pathogenesis itself, as the accumulation of misfolded proteins could potentially exacerbate amyloid deposition. In addition, reduced expression of ubiquitin catabolizing enzymes can also impair synaptic and cognitive function. For example, by inhibiting ubiquitin recycling, $A \beta$ oligomers interfere indirectly with long-term potentiation. ${ }^{31}$ The present study provides the first evidence that injection of $\mathrm{A} \beta$ that has been preaggregated to obtain a highly fibrillar species can produce lasting impairments in neuronal PGP 9.5 expression. However, precisely how extracellular
A $\beta$ species exert their effects on the cytoplasmic ubiquitin system remains to be established.

Widespread downregulation of the calcium-binding protein PV was also evident at 48 hours following $A \beta$ injection. This response was less specific to $A \beta_{1-42}$, with significant loss of PV-IR seen among the $A \beta_{42-1}$ reverse peptide group, consistent with previous findings from this laboratory. ${ }^{22}$ Injection of $\mathrm{sA} \beta$ appeared to have a more rapid impact on PV than either of the preaggregated treatments, producing a marked reduction in average PV-IR cell diameters at 48 hours; an effect that was only observed for preaggregated $A \beta$ after 1-month survival. The reduction in PV cell diameters suggests that larger neurons (predominantly in the GCL) are more susceptible to ionic imbalance following $A \beta$ than are smaller PV-IR interneurons, consistent with the pattern of $A \beta$-induced PGP 9.5 disruption. Indeed, ganglion cell calcium buffering capacity declines in 
A

\section{Retinal thickness}

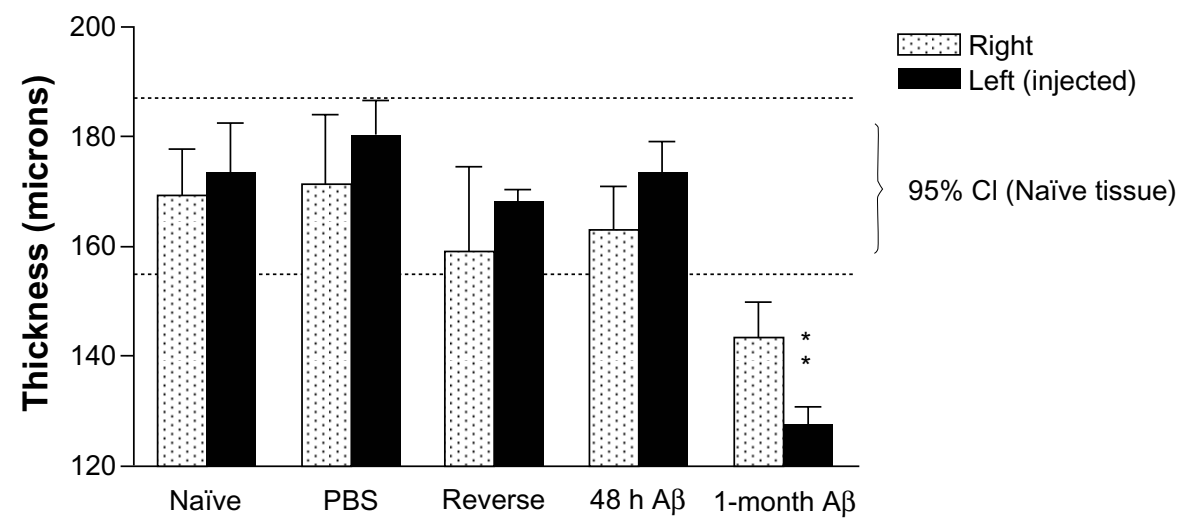

B
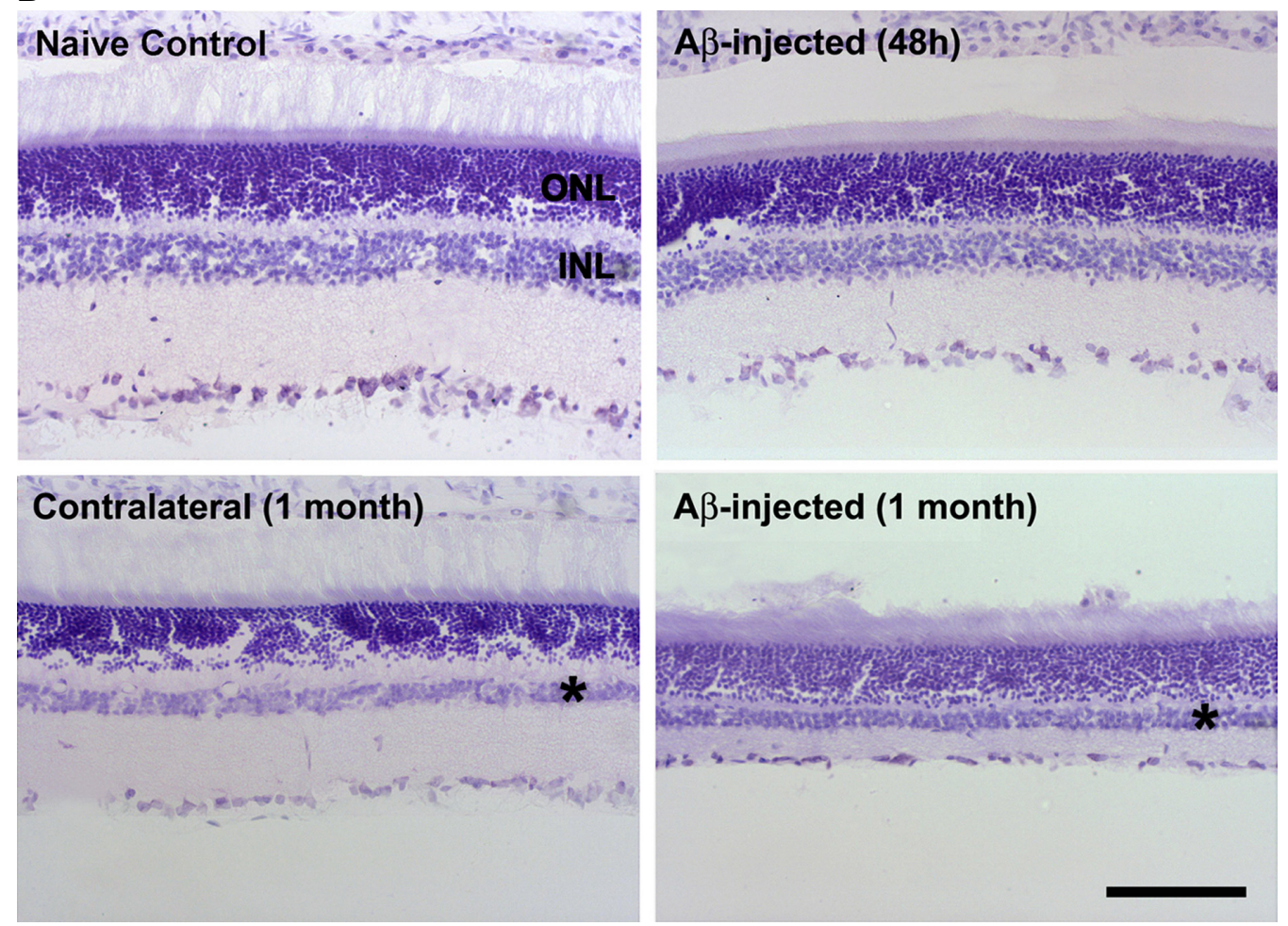

Figure 9 (A) Graph showing dramatic reduction in retinal thickness for $A \beta_{1-42}$-injected group at I-month survival compared with naïve controls, or 48 hours after injection with phosphate buffered saline (PBS), A $\beta_{42-1}$ control peptide, or $A \beta_{1-42}$ All peptides $(5 \mathrm{nmol} / 3 \mu \mathrm{L})$ were preaggregated for 8 days. Bars represent mean \pm standard error of the mean (SEM). 95\% confidence interval $(\mathrm{Cl})$. **P < 0.0I: significant reduction compared with PBS controls (Tukey's post hoc test from I-way ANOVA). (B) Nissl-stained sections from central retina illustrating variation in retinal thickness (upper panel) with atrophy in both contralateral (noninjected) retinas and $A \beta_{1-42}$-injected retinas after I-month survival (lower panel). Note that while the outer nuclear layer (ONL) is largely preserved, there is a marked reduction in the thickness of the inner nuclear layer (INL) at I-month postinjection (asterisks in lower panel). Scale bar $=100 \mu \mathrm{m}$.

the adult retina and may, therefore, enhance vulnerability to neurotoxicity. ${ }^{32}$ That $\mathrm{sA} \beta$ had a faster impact on ganglion neurons again points to a more direct mechanism of action than for fibrillar $\mathrm{A} \beta$ preparations. The pore-forming activity of sA $\beta$ species $^{33}$ is an interesting possibility, as this could channel a rapid influx of calcium inside cells, overwhelming homeostatic mechanisms far more quickly than indirect A $\beta$ signaling mechanisms.

\section{$A \beta$ initiates chronic atrophy of cholinergic neurons}

The profile of $\mathrm{A} \beta$-induced changes in ChAT expression differed from those of PV in that the detrimental effects were highly specific to the 1-42 sequence and amplified by prolonged preaggregation ( 8 days), including less long-term recovery and a marked bilateral effect at 1 month. We have previously established a dose-dependant effect of $A \beta$ on 
ChAT IR for both sA $\beta_{1-42}$ and 4-day preaggregated $A \beta_{1-42}$ at 48 hours using $2 \mathrm{nmol}$ and $5 \mathrm{nmol}$ preparations. Although the degree of ChAT loss was similar between these species, the effects of extending the preaggregation period to 8 days were striking, most notably the widespread loss of ChAT staining among processes as well as cell bodies. After 1 month, modest recovery of staining was detected among cholinergic fibers; however, labeled somata were markedly atrophied, displaying a significant decline in cell diameters. Atrophy of cholinergic cell bodies has not been formerly demonstrated following in vivo injection of fibril$\operatorname{lar} \mathrm{A} \beta$, nevertheless, this is likely to be a robust finding as data were pooled from $A \beta_{1-42}$ obtained from 2 different manufacturers, producing an almost identical reduction in mean diameters (Bachem, $7.49 \pm 0.09 \mu \mathrm{m}$ and California peptide, $7.47 \pm 0.08 \mu \mathrm{m} ; \mathrm{n}=7$ per group). Increased toxicity following injection of highly fibrillar $A \beta_{1-42}$ was also reflected in patterns of glial activation, with significantly greater upregulation of both nestin and GFAP in retinas treated with the 8 -day preaggregated $A \beta$ relative to the 4-day treatment. ${ }^{24}$ This enhanced injury response suggests that inflammatory mechanisms are likely to have played a central role in cholinergic dysfunction following injection of fibrillar $\mathrm{A} \beta$ species and by triggering a systemic stress response, might also account for the chronic decline in ChAT activity in noninjected eyes.

An additional distinctive feature of $\mathrm{A} \beta$-induced ChAT decline was the uneven distribution of loss, with robust IR retained in discrete segments of retina. As this pattern was maintained at 1-month postinjection, it suggests that rather than undergoing cell death, cholinergic neurons were surviving in an atrophied, somewhat quiescent state with reduced ChAT expression. This conclusion is supported by a recent report using 4-day preaggregated $A \beta_{1-42}$ which found that retinal ChAT cell numbers had recovered at 5-month postinjection, despite a huge reduction retinal thickness. ${ }^{34}$ The focal upregulation of nestin within regions of robust ChAT expression at 1 month raises the possibility that prolonged nestin induction may be associated with neuroprotective efforts. Widely used as a marker of immature cells, nestin induction in the injured adult retina occurs predominantly in Müller glia rather than in astrocytes. ${ }^{35}$ The selectivity of this response may reflect the relative proximity of viable ChAT cells to the retinal periphery where the microenvironment is more permissive to regeneration and promotes the capacity of Müller glia to revert to a developmental progenitor-like state in response to injury. ${ }^{36,37}$ As Müller glia are responsible for stimulating ChAT activity in the developing retina, ${ }^{38}$ it is plausible that following reexpression of developmental markers, they may resume this role in the injured retina, attenuating cholinergic decline.

\section{Mechanisms of $A \beta$ toxicity}

Although it is possible that sA $\beta$ oligomers may penetrate the retinal-vitreal barrier, previous research from this laboratory found no evidence that preaggregated $A \beta$ was either internalized by Müller glia or crossed Müller cell endfeet entering the retina. ${ }^{22}$ It, therefore, seems likely that direct contact between $A \beta$ and retinal neurons is not essential to initiate neurotoxicity. Instead, injected $A \beta$ aggregates were found to accumulate on the Müller glia endfeet, suggesting that interaction with Müller cell membranes may precipitate a cascade of events leading to neuronal dysfunction.

In common with other aggregation-prone proteins such as prions, $A \beta$ 's amphiphilic nature and propensity to interact with cell membranes form the basis of its toxicity. ${ }^{39,40}$ Increasingly, amyloids are found to preferentially accumulate in glial and neuronal plasma membrane lipid "raft" domains, where they can interfere with the trafficking of lipids and receptor proteins ${ }^{41-43}$ and smaller fragments may be internalized. ${ }^{44-46}$ This ability to permeabilize cell membranes may initiate a host of downstream processes including disruption of ion homeostasis, production of reactive oxygen species, and mitochondrial dysfunction. ${ }^{40}$ Any disruption of Müller glia will have a profound impact on the viability of retinal neurons, which depend on Müller cells for nutritive support and the removal of toxic metabolites. ${ }^{47}$ For instance, following intravitreal injection of $A \beta$ aggregates, Müller glia display impaired glutamate metabolism including an accumulation of gamma-aminobutyric acid ${ }^{34}$ and a reduction in glutamine synthetase, ${ }^{23}$ the enzyme responsible for converting glutamate to glutamine, thereby increasing the susceptibility of retinal neurons to excitotoxic injury.

Small oligomers are increasingly regarded as being more toxic than amyloid fibrils due to their greater range of membrane interactions and therefore accessibility to intracellular systems, including mechanisms such as pore formation and possible ligand-like activity. ${ }^{33,40,48}$ However, we did not find sA $\beta$ species to exert significantly greater toxicity with the exception of neuronal PV. One possibility is that the actions of sA $\beta$ were manifest to a greater extent in PV expression because calcium buffering responds more rapidly to environmental impact, whereas declining ChAT levels evolve more slowly, evidenced by the continuing presence of ChAT in neuronal processes despite reduced ChAT manufacture in the cell bodies. This is supported by our earlier findings that $A \beta$ aggregates induce 
significant changes in PV both more rapidly (within 24 hours) and at lower doses $(2 \mathrm{nmol})$ than required to significantly impair ChAT (48 hours/5 nmol).22,34 Differential vulnerability of cellular systems might also account for the relatively greater sensitivity of metabolic markers to the weaker amphiphilic interactions of the $A \beta_{42-1}$ reverse peptide.

Alternatively, it is possible that the toxicity of $\operatorname{sA} \beta$ was attenuated because the primary interface was glial rather than neuronal, triggering degradation or even fibrillization. The matrix of extracellular components at vitreal-retinal interface provides an ideal substrate for aggregation of oligomers. However, earlier findings comparing injections of $\mathrm{sA} \beta_{1-40}$ and fibrillar $A \beta_{1-40}$ in rat striatum ${ }^{49}$ found no evidence that injected $\mathrm{sA} \beta$ underwent fibrillization in vivo and only a small fraction were degraded by microglia. Instead, the majority of sA $\beta$ was rapidly cleared from the brain parenchyma within 1 day, whereas fibrillar $\mathrm{A} \beta$ remained in situ for at least 30 days and was progressively phagocytosed. Although the vitreous is regarded as a closed system, exchange with the systemic circulation does occur via the anterior chamber, albeit more slowly than for brain and with molecular weight as a rate-limiting factor. ${ }^{50}$ Therefore, it cannot be ruled out that the vitreal concentration of sA $\beta$ declined more rapidly than for fibrillar species.

The potent neurotoxicity exhibited by both preaggregated treatments suggests that fibrillar $A \beta$ species markedly impaired the normal functions of Müller glia, possibly by altering membrane conductance, reducing the efficiency of signal transduction, and stimulating the release of inflammatory factors. ${ }^{40,51}$ The dramatic increase in ChAT loss obtained by extending the $A \beta$ preaggregation period to 8 days indicates that the extent of fibrillization can also have a significant impact on $\mathrm{A} \beta$ toxicity. In vivo attachment to cell membranes may also have modulated the activity of the injected aggregates, as $A \beta$ fibrils formed on plasma membranes are more toxic than fibrils formed without membranes, due to modifications in secondary structure producing stronger binding and greater surface hydrophobicity. ${ }^{42}$

The importance of inflammatory mediators for fibrillar $\mathrm{A} \beta$ actions is also highlighted by the deterioration of ChAT in noninjected eyes at 1 month. Indeed, bilateral activation of astrocytes and microglia has previously been detected at 5-month postinjection of $\mathrm{A} \beta$ aggregates. ${ }^{23}$ Moreover, we have recently demonstrated deleterious effects of highly aggregated $A \beta$ on the integrity of retinal vasculature that may contribute to bilateral action. ${ }^{24}$ However, it is important to note that although the extent of fibrillization had marked impact on ChAT and gliosis, this was not mirrored by PV, reinforcing suggestions that different conformations of $A \beta$ may contribute to AD pathology via different mechanisms. ${ }^{15}$ Thus, the downregulation of cholinergic phenotype may be mediated in large part by inflammatory factors released from activated glia, whereas loss of retinal PV appears to have been induced by alternate mechanisms, for example, direct perturbation of the extracellular environment following disruption of glial homeostatic functions.

\section{Conclusion}

In terms of the amyloid cascade hypothesis, the present findings lend weight to suggestions that $\mathrm{sA} \beta$ oligomers initiate toxicity not only at synapses, but are neurotoxic by a variety of mechanisms. Moreover, both sA $\beta$ and fibrillar $\mathrm{A} \beta$ species appear to be capable of disrupting synapses via indirect pathways that are independent of glial activation. Among fibrillar A $\beta$ species, the extent of aggregation also has a significant impact on selective cellular functions. Thus, assembly size appears to be a critical determinant of $A \beta$ 's range of cellular interactions, possibly with small oligomers interacting more efficiently with cell surface proteins, whereas larger fibrils immobilize membrane machinery, block receptor sites, and attract inflammation. The nature of $A \beta$ assembly states may, therefore, have a significant influence on $\mathrm{A} \beta$ pathology in terms of timing of disease progression and cells most affected, for instance, species that appear most neurotoxic are not necessarily the most vasotoxic. Using the retinal-vitreal model to determine how glia serve as intermediaries in $\mathrm{A} \beta$-induced neurotoxicity should shed significant light on mechanisms of $A \beta$ pathology and permit testing of potential therapeutic strategies for both human AD and other aggregation-prone disorders.

\section{Acknowledgments}

This study was supported by a grant from the GlaxoSmithKline Pharmaceuticals (UK) and in part by NIH grant \# AG12411.

\section{Disclosure}

The authors declare that there are no conflicts of interest in this work.

\section{References}

1. Guo L, Salt TE, Luong V, et al. Targeting amyloid-beta in glaucoma treatment. Proc Natl Acad Sci U S A. 2007;104:13444-13449.

2. Haass C, Selkoe DJ. Soluble protein oligomers in neurodegeneration: lessons from the Alzheimer's amyloid beta-peptide. Nat Rev Mol Cell Biol. 2007;8:101-112.

3. Burdick D, Soreghan B, Kwon M, et al. Assembly and aggregation properties of synthetic Alzheimer's A4/beta amyloid peptide analogs. J Biol Chem. 1992;267:546-554. 
4. Hardy J,Allsop D. Amyloid deposition as the central event in the aetiology of Alzheimer's disease. Trends Pharmacol Sci. 1991;12:383-388.

5. Pike CJ, Burdick D, Walencewicz AJ, Glabe CG, Cotman CW. Neurodegeneration induced by beta-amyloid peptides in vitro: the role of peptide assembly state. J Neurosci. 1993;13:1676-1687.

6. Jen LS, Hart AJ, Jen A, et al. Alzheimer's peptide kills cells of retina in vitro. Nature. 1998;392:140-141.

7. McGeer EG, McGeer PL. Innate immunity in Alzheimer's disease: a model for local inflammatory reactions. Mol Interv. 2001;1:22-29.

8. Heneka MT, O'Banion MK. Inflammatory processes in Alzheimer's disease. J Neuroimmunol. 2007;184:69-91.

9. Walsh DM, Selkoe DJ. A beta oligomers - a decade of discovery. J Neurochem. 2007;101:1172-1184

10. Lue LF, Kuo YM, Roher AE, et al. Soluble amyloid beta peptide concentration as a predictor of synaptic change in Alzheimer's disease. Am J Pathol. 1999;155:853-862.

11. McLean CA, Cherny RA, Fraser FW, et al. Soluble pool of Abeta amyloid as a determinant of severity of neurodegeneration in Alzheimer's disease. Ann Neurol. 1999;46:860-866.

12. Naslund J, Haroutunian V, Mohs R, et al. Correlation between elevated levels of amyloid beta-peptide in the brain and cognitive decline. JAMA. 2000;283:1571-1577.

13. Shankar GM, Li S, Mehta TH, et al. Amyloid-beta protein dimers isolated directly from Alzheimer's brains impair synaptic plasticity and memory. Nat Med. 2008;14:837-842.

14. Klein WL. Synaptic targeting by Abeta oligomers (ADDLs) as a basis for memory loss in early Alzheimer's disease. Alzheimers Dement. 2006;2:43-55.

15. Deshpande A, Mina E, Glabe C, Busciglio J. Different conformations of amyloid beta induce neurotoxicity by distinct mechanisms in human cortical neurons. J Neurosci. 2006;26:6011-6018.

16. Walsh DM, Hartley DM, Kusumoto Y, et al. Amyloid beta-protein fibrillogenesis. Structure and biological activity of protofibrillar intermediates. J Biol Chem. 1999;274:25945-25952.

17. Klein WL. Abeta toxicity in Alzheimer's disease: globular oligomers (ADDLs) as new vaccine and drug targets. Neurochem Int 2002;41:345-352.

18. Funato H, Enya M, Yoshimura M, Morishima-Kawashima M, Ihara Y. Presence of sodium dodecyl sulfate-stable amyloid beta-protein dimers in the hippocampus CA1 not exhibiting neurofibrillary tangle formation. Am J Pathol. 1999;155:23-28.

19. Gong Y, Chang L, Viola KL, et al. Alzheimer's disease-affected brain: presence of oligomeric A beta ligands (ADDLs) suggests a molecular basis for reversible memory loss. Proc Natl Acad Sci U SA. 2003;100:10417-10422.

20. Lacor PN, Buniel MC, Chang L, et al. Synaptic targeting by Alzheimer's-related amyloid beta oligomers. J Neurosci. 2004;24: 10191-10200.

21. Duff K, Suleman F. Transgenic mouse models of Alzheimer's disease: how useful have they been for therapeutic development? Brief Funct Genomic Proteomic. 2004;3:47-59.

22. Walsh DT, Montero RM, Bresciani LG, et al. Amyloid-beta peptide is toxic to neurons in vitro via indirect mechanisms. Neurobiol Dis. 2002;10:20-27.

23. Walsh DT, Bresciani L, Saunders D, et al. Amyloid beta peptide causes chronic glial cell activation and neuro-degeneration after intravitreal injection. Neuropathol Appl Neurobiol. 2005;31:491-502.

24. Anderson PJ, Watts HR, Hille CJ, et al. Glial and endothelial bloodretinal barrier responses to amyloid- $\beta$ in the neural retina of the rat. Clin Ophthalmol. 2008;2(4):801-816.

25. Watts HR, Vince V, Walsh DT, et al. Alterations in presenilin 1 processing by amyloid-beta peptide in the rat retina. Exp Brain Res. 2007;181: 69-77.

26. Klein WL, Krafft GA, Finch CE. Targeting small Abeta oligomers: the solution to an Alzheimer's disease conundrum? Trends Neurosci. 2001;24:219-224.
27. Oakley H, Cole SL, Logan S, et al. Intraneuronal beta-amyloid aggregates, neurodegeneration, and neuron loss in transgenic mice with five familial Alzheimer's disease mutations: potential factors in amyloid plaque formation. J Neurosci. 2006;26:10129-10140.

28. Bate C, Tayebi M, Williams A. Ginkgolides protect against amyloid-beta1-42-mediated synapse damage in vitro. Mol Neurodegener. 2008;3:1.

29. Balazs EA. Functional anatomy of the vitreous. In: Duane TD, Jaeger EA, editors. Biomedical Foundations of Ophthalmology. Philadelpia: Harper and Row; 1982:6-12.

30. Chen ST, von Bussmann KA, Garey LJ, Jen LS. Protein gene product 9.5-immunoreactive retinal neurons in normal developing rats and rats with optic nerve or tract lesion. Brain Res Dev Brain Res. 1994; 78:265-272.

31. Gong B, Cao Z, Zheng P, et al. Ubiquitin hydrolase Uch-L1 rescues beta-amyloid-induced decreases in synaptic function and contextual memory. Cell. 2006;126:775-788.

32. Mann M, Haq W, Zabel T, Guenther E, Zrenner E, Ladewig T. Age-dependent changes in the regulation mechanisms for intracellular calcium ions in ganglion cells of the mouse retina. Eur $J$ Neurosci. 2005;22:2735-2743.

33. Arispe N, Diaz JC, Simakova O. Abeta ion channels. Prospects for treating Alzheimer's disease with Abeta channel blockers. Biochim Biophys Acta. 2007;1768:1952-1965.

34. Aruoma OI, Jen SS, Watts HR, et al. Acute and chronic effects of intravitreally injected beta-amyloid on the neurotransmitter system in the retina. Toxicology. 2009;256:92-100.

35. Frisen J, Johansson CB, Torok C, Risling M, Lendahl U. Rapid, widespread, and longlasting induction of nestin contributes to the generation of glial scar tissue after CNS injury. J Cell Biol. 1995;131:453-464.

36. Ooto S, Akagi T, Kageyama R, et al. Potential for neural regeneration after neurotoxic injury in the adult mammalian retina. Proc Natl Acad Sci U S A. 2004;101:13654-13659.

37. Ghai K, Stanke JJ, Fischer AJ. Patterning of the circumferential marginal zone of progenitors in the chicken retina. Brain Res. 2008;1192:76-89.

38. Hofmann HD. Development of cholinergic retinal neurons from embryonic chicken in monolayer cultures: stimulation by glial cell-derived factors. J Neurosci. 1988;8:1361-1369.

39. Fantini J, Garmy N, Mahfoud R, Yahi N. Lipid rafts: structure, function and role in HIV, Alzheimer's and prion diseases. Expert Rev Mol Med. 2002;4:1-22.

40. Glabe CG. Common mechanisms of amyloid oligomer pathogenesis in degenerative disease. Neurobiol Aging. 2006;27:570-575.

41. Igbavboa U, Pidcock JM, Johnson LN, et al. Cholesterol distribution in the golgi complex of DITNC1 astrocytes is differentially altered by fresh and aged amyloid beta-peptide-(1-42). $J$ Biol Chem. 2003;278:17150-17157.

42. Okada T, Ikeda K, Wakabayashi M, Ogawa M, Matsuzaki K. Formation of toxic Abeta(1-40) fibrils on GM1 ganglioside-containing membranes mimicking lipid rafts: polymorphisms in Abeta(1-40) fibrils. $J$ Mol Biol. 2008;382:1066-1074.

43. Williamson R, Usardi A, Hanger DP, Anderton BH. Membrane-bound beta-amyloid oligomers are recruited into lipid rafts by a fyn-dependent mechanism. FASEB J. 2008;22:1552-1559.

44. Nielsen HM, Veerhuis R, Holmqvist B, Janciauskiene S. Binding and uptake of Abeta1-42 by primary human astrocytes in vitro. Glia. 2008;57:978-988.

45. Chafekar SM, Baas F, Scheper W. Oligomer-specific Abeta toxicity in cell models is mediated by selective uptake. Biochim Biophys Acta. 2008;1782:523-531.

46. Yamada K, Hashimoto T, Yabuki C, et al. The low density lipoprotein receptor-related protein 1 mediates uptake of amyloid beta peptides in an in vitro model of the blood-brain barrier cells. J Biol Chem. 2008;283:34554-34562. 
47. Bringmann A, Pannicke T, Grosche J, et al. Muller cells in the healthy and diseased retina. Prog Retin Eye Res. 2006;25: $397-424$.

48. Lacor PN, Clemente AS, Viola KL, Klein WL. Changes in NMDA receptor subunit 1 and $2 \mathrm{~B}$ expression in ADDL-treated hippocampal neurons. Soc Neurosci Abstr. 2005;31. Abstract 786.17.

49. Weldon DT, Rogers SD, Ghilardi JR, et al. Fibrillar beta-amyloid induces microglial phagocytosis, expression of inducible nitric oxide synthase, and loss of a select population of neurons in the rat CNS in vitro. $J$ Neurosci. 1998;18:2161-2173.
50. Bender B, Gaudrealt J, Damico L, et al. A pharmacokinetic model describing ocular and systemic distribution of Lucentis in rabbits and monkeys [abstract]. Am Assoc Pharmaceut Scientists. 2007;19(52):1234.

51. Kayed R, Sokolov Y, Edmonds B, et al. Permeabilization of lipid bilayers is a common conformation-dependent activity of soluble amyloid oligomers in protein misfolding diseases. J Biol Chem. 2004;279:46363-46366. 


\section{Supplementary Figure}

\section{Retinal synaptophysin}

OPL

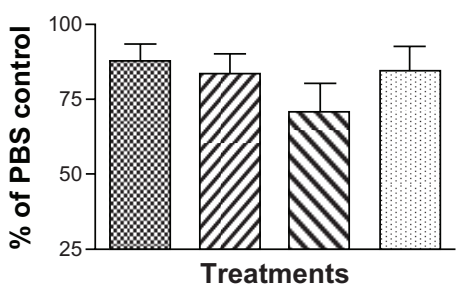

Non-injected

(R-eye)
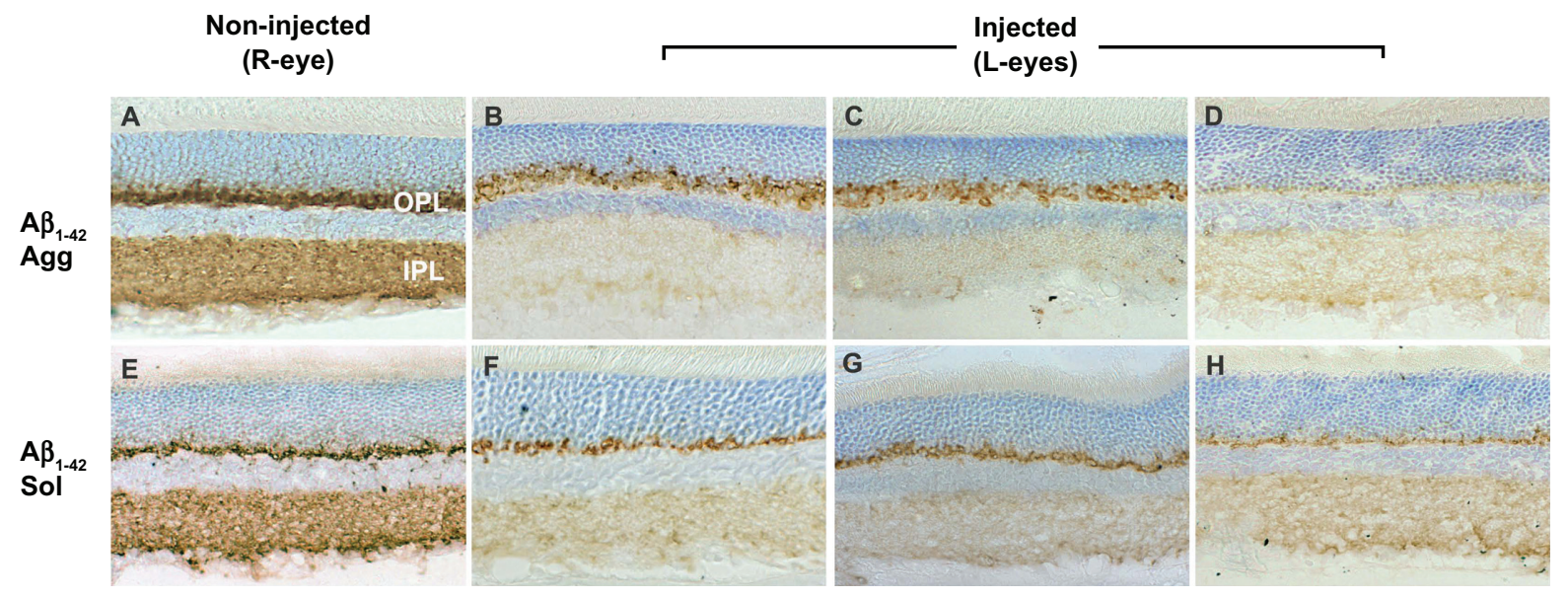

IPL

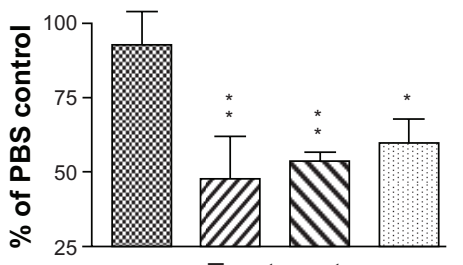

Treatments

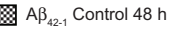

$\square A \beta_{1-42} A g g(5 \mathrm{nmol}) 24 \mathrm{~h}$

$\triangle A \beta_{1-42}$ Agg $(5 \mathrm{nmol}) 48 \mathrm{~h}$

$A \beta_{1-42}$ Sol $(2 \mathrm{nmol}) 48 \mathrm{~h}$

Figure SI Bar graphs showing mean optical density of retinal synaptophysin immunoreactivity as a percentage of phosphate buffered saline (PBS) controls. A $\beta_{1-42}$ treatments did not result in statistically significant loss of synaptophysin in the OPL, in contrast to the marked loss observed in the IPL. Retinal sections at 48-hour postinjection from groups receiving: $(\mathbf{A}-\mathbf{D})$ preaggregated $A \beta_{1-42}(5 \mathrm{nmol})$ or $(\mathbf{E}$ and $\mathbf{H})$ soluble $A \beta_{1-42}(2 \mathrm{nmol})$. Noninjected (R-eyes) showing normal synaptophysin expression $(\mathbf{A}$ and $\mathbf{E})$. Injected (L-eyes) showing typical marked loss of synaptophysin reactivity in IPL (B, C and F, G). Less frequently, marked loss of immunoreactivity was seen in both the IPL and OPL (D and $\mathbf{H})$.

Note: Values are given as mean \pm standard error of the mean (SEM).

*P $<0.05$; ** $<0.01$ : significant reduction compared with $A \beta_{42-1}$ control peptide group (ANOVA and post hoc Dunnett's test). Image magnification before cropping: 20x; except (F) 40x.

Abbreviations: IPL, inner plexiform layer; OPL, outer plexiform layer; Agg, aggregated; sol, soluble.

Eye and Brain

\section{Publish your work in this journal}

Eye and Brain is an international, peer-reviewed, open access journal focusing on clinical and experimental research in the field of neuro-ophthalmology. All aspects of patient care are addressed within the journal as well as basic research. Papers covering original research, basic science, clinical and epidemiological studies, reviews and evaluations,

guidelines, expert opinion and commentary, case reports and extended reports are welcome. The manuscript management system is completely online and includes a very quick and fair peer-review system, which is all easy to use. Visit http://www.dovepress.com/testimonials.php to read real quotes from published authors. 